\title{
Temporal Trends and Potential
} Drivers of Stranded Marine Debris on Beaches Within Two US National Marine Sanctuaries Using Citizen Science Data

OPEN ACCESS

Edited by:

Jane A. Entwistle, Northumbria University,

United Kingdom

Reviewed by:

Miranda Prendergast-Miller,

Northumbria University,

United Kingdom

David Megson,

Manchester Metropolitan University,

United Kingdom

*Correspondence:

Amy V. Uhrin

amy.uhrin@noaa.gov

Specialty section:

This article was submitted to

Toxicology, Pollution and the

Environment,

a section of the journal

Frontiers in Environmental Science

Received: 10 September 2020

Accepted: 26 October 2020

Published: 25 November 2020

Citation:

Uhrin AV, Lippiatt S, Herring CE,

Dettloff $K$, Bimrose $K$ and Butler-Minor C (2020) Temporal

Trends and Potential Drivers of Stranded Marine Debris on Beaches

Within Two US National Marine

Sanctuaries Using Citizen Science Data. Front. Environ. Sci. 8:604927.

doi: 10.3389/fenvs.2020.604927

\begin{abstract}
Amy V. Uhrin ${ }^{1 *}$, Sherry Lippiatt ${ }^{1,2}$, Carlie E. Herring ${ }^{1,2}$, Kyle Dettloff $^{3}$, Kate Bimrose ${ }^{4,5}$ and Chris Butler-Minor ${ }^{6,7}$

${ }^{1}$ Department of Commerce, National Oceanic and Atmospheric Administration, National Ocean Service, Office of Response and Restoration, Marine Debris Division, Silver Spring, MD, United States, ${ }^{2}$ I.M. Systems Group, Rockville, MD, United States, ${ }^{3}$ Department of Commerce, National Oceanic and Atmospheric Administration, National Marine Fisheries Service, Southeast Fisheries Science Center, Fisheries Statistics Division, Miami, FL, United States, ${ }^{4}$ Greater Farallones Association, San Francisco, CA, United States, ${ }^{5}$ Department of Commerce, National Oceanic and Atmospheric Administration, Office of National Marine Sanctuaries, Greater Farallones National Marine Sanctuary, San Francisco, CA, United States, ${ }^{6}$ National Marine Sanctuary Foundation, Silver Spring, MD, United States, ${ }^{7}$ Department of Commerce, National Oceanic and Atmospheric Administration, Office of National Marine Sanctuaries, Olympic Coast National Marine Sanctuary, Port Angeles, WA, United States
\end{abstract}

Marine debris is a threat to our ocean that can be more effectively addressed through monitoring and assessment of items stranded on shorelines. This study engaged citizen scientists to conduct shoreline marine debris surveys according to a published NOAA protocol within the Greater Farallones and Olympic Coast National Marine Sanctuaries on the west coast of the United States. Here, we use the results of these multi-year monitoring data to estimate marine debris abundance and temporal trends, and identify drivers of debris loads. Changes in debris counts and composition are shown to reflect seasonal patterns of coastal upwelling and downwelling, but longer temporal trends in overall debris loads depend on the sampling window. Identifying drivers of stranded debris is challenging given the observational nature of the data. A linear increase in total expected debris counts was observed when up to five participants are conducting a survey, suggesting a need to standardize the number of participants and their search pattern for debris in shoreline monitoring efforts. Lastly, we discuss the application of shoreline marine debris data to evaluate the impact of management decisions and identify new targets for mitigation.

\footnotetext{
Keywords: marine debris, citizen science, temporal trend, plastic pollution, generalized additive models, US west coast, shoreline monitoring, National Marine Sanctuaries
}

\section{INTRODUCTION}

Marine debris is defined as any "persistent solid material that is manufactured or processed and directly or indirectly, intentionally, or unintentionally, disposed of or abandoned into the marine environment or the Great Lakes" (33 USC 1,951 et seq. as amended by Title VI of Public Law $112-213)$. Marine debris is recognized as a transboundary, global concern, and plastic debris in 
the world ocean has recently been described as a creeping crisis (Mæland and Staupe-Delgado, 2020). There is mounting evidence that marine debris, and plastic pollution specifically, causes ecological effects across all levels of biological organization in marine and freshwater species (Gall and Thompson, 2015; Bucci et al., 2020). It can also be detrimental to marine and coastal habitats (National Oceanic and Atmospheric Administration (NOAA), 2016 and citations within), and humans (Sheavly and Register, 2007; Newman et al., 2015; Campbell et al., 2019). Marine debris can also affect various economic sectors, such as fisheries (Newman et al., 2015; Scheld et al., 2016), marine transportation (i.e., shipping, passenger, naval, and other maritime vessels) due to navigational hazards and consequent vessel repair (Newman et al., 2015; Hong et al., 2017), tourism (Newman et al., 2015; English et al., 2019), and beach recreation (Leggett et al., 2018).

Marine debris encompasses a wide size distribution from large abandoned and derelict vessels, to single-use products, to unrecognizable fragments, and microplastics (smaller than $5 \mathrm{~mm}$ in size). It comprises numerous material types, including plastic, glass, metal, and rubber, among others. Due to its wide use and persistent nature, plastic debris is the most frequent type of marine debris found in marine and freshwater environments (Hoellein et al., 2015; Blickley et al., 2016; Hardesty et al., 2017a; Nelms et al., 2017). It is important to identify the sources and pathways of debris (when possible), trends in debris loads, and areas of accumulation to determine appropriate mitigation measures, and to track the success of these efforts over time (Ribic et al., 2012; Lippiatt et al., 2013). This can be achieved by implementing environmental monitoring programs.

Over the past few decades, long-term monitoring programs have been established to detect trends in marine debris distribution, composition, and abundance (Sheavly, 2007; OSPAR Commission, 2010; Lippiatt et al., 2013). Most of these monitoring programs utilize citizen scientists to gather data. Marine debris lends itself to citizen science, especially given the current attention on the issue, the opportunities for participation (due to its global and pervasive nature), and varying levels of time commitment (a few hours once to twice a year to conducting monthly surveys). The volume of data gathered through citizen science initiatives is a valuable addition to the global field of marine debris studies and can be of equivalent quality as professional collections (van der Velde et al., 2017). In addition, citizen science empowers participants through the creation of a stewardship ethic and the development of pro-environmental attitudes and behaviors (Whitelaw et al., 2003; Cooper et al., 2007; Toomey and Domroese, 2013). Though there are some tradeoffs between rigorous, professionally established monitoring programs and volunteer beach cleanup programs (with data collection), an effective monitoring design can alleviate many of these issues (Nelms et al., 2017; Haarr et al., 2020) and longterm monitoring programs can provide insight into spatial and temporal debris. For instance, long-term citizen science datasets in Great Britain revealed no significant change in total debris loads over a 10 year time period, though regional differences in abundance and types of debris were detected (Nelms et al., 2017). In Norway, a general decline in debris was detected from 2011 to
2018 via citizen science beach cleanup data (Haarr et al., 2020). Ribic et al. $(2010,2012)$ were able to document regional changes in marine debris loads on beaches along the Atlantic coast from 1997 to 2007, and the Pacific Coast and Hawaii from 1998 to 2007. They specifically evaluated patterns regarding sources of debris, based on factors like proximity to fisheries-related activities, distance to population centers, type of beach (e.g., reserves and tourist beaches, etc.); seasons, and weather events (Ribic et al., 2010, 2012). The International Coastal Cleanup data, collected globally each September, have provided information on marine debris accumulation areas (hot-spots), prevalence of debris types by region, and identified where management actions could potentially be implemented (Hardesty et al., 2017b).

Monitoring programs also gather information and data that can inform management decisions and track the success of implemented policies (Lovett et al., 2007; Ribic et al., 2010; Hutto and Belote, 2013). For marine debris, this could include tracking changes in debris loads pre-and-post-implementation of policies (Blickley et al., 2016), or comparing areas with and without enacted policies (Schuyler et al., 2018). For instance, Blickley et al. (2016) evaluated the effectiveness of local plastic bag bans and tobacco free beaches in Maui County, Hawai'i, by comparing debris loads post-policy implementation to baseline monitoring data. No plastic bags were recorded from any site during the study period (post-ban) while only one site had significantly fewer cigarette items post-ban (Blickley et al., 2016). Schuyler et al. (2018) analyzed marine debris monitoring datasets from the U.S. and Australia and found that states with container deposit legislation (cash incentives for returned beverage containers) had significantly fewer beverage bottles on shorelines compared to states and territories without this legislation. Thus, monitoring data can provide insight into the level of effectiveness of enacted policies, changes needed in management plans, and/or lead to the implementation of new policies (Lovett et al., 2007; Hutto and Belote, 2013; Blickley et al., 2016).

The National Oceanic and Atmospheric Administration's (NOAA) Marine Debris Program (MDP), established through the 2006 Marine Debris Act, addresses mandates to "identify, determine sources of, assess, prevent, reduce, and remove marine debris and address the adverse impacts of marine debris on the economy of the United States, marine environment, and navigation safety" (33 USC 1,951 et seq. as amended by Title VI of Public Law 112-213). The Program's Marine Debris Monitoring and Assessment Project (MDMAP), addresses this mandate by assessing the abundance, types, and status and trends of marine debris on U.S. shorelines. The intent of MDMAP was to foster a national shoreline monitoring program to support research and science-based policies, and guide prevention efforts. The initial monitoring protocol (developed from 2009 to 2012) was designed as a rapid, standardized, and statistically valid marine debris shoreline monitoring protocol (Lippiatt et al., 2013). This protocol built off previous national monitoring efforts [see Escardo-Boomsma et al. (1995), Sheavly (2007), and Cheshire et al. (2009)]. The MDMAP monitoring protocol was initially created for trained, scientific staff, however, the protocol was quickly adapted for use by (trained) citizen scientists after the 2011 Tohoku Japan earthquake and tsunami and interest by 
partners along the West Coast to be able to detect changes in debris loads due to tsunami debris traversing the North Pacific Ocean. Now, MDMAP is the Program's flagship citizen science program that engages NOAA partners and volunteers across the nation to survey and record the amount and types of marine debris on shorelines.

In 2012, the NOAA MDP initiated monitoring partnerships with two National Marine Sanctuaries: Olympic Coast National Marine Sanctuary (OCNMS) and the Greater Farallones National Marine Sanctuary (GFNMS). These partners established shoreline monitoring sites and collected monthly data over a period of 5-7 years. The primary objective of this research was to evaluate temporal trends and potential drivers of stranded marine debris on beaches within the two sanctuaries using data collected following MDMAP protocols. Specifically, we (1) quantified debris composition and evaluated trends over time in each sanctuary, (2) identified differences in composition and trends between sanctuaries, (3) determined which site-level covariates are most strongly associated with debris load, and (4) determined the relationship (linear/non-linear) of survey effort variables with total debris counts.

\section{METHODS}

\section{Study Areas}

The U.S. National Marine Sanctuary system, managed by NOAA, protects the Nation's most treasured biological and socioeconomic resources. The system includes 14 protected areas covering 600,000 square miles of ocean and Great Lakes environments. Shoreline marine debris survey data described here were collected from two National Marine Sanctuaries, the Greater Farallones National Marine Sanctuary (GFNMS) and the Olympic Coast National Marine Sanctuary (OCNMS) (Figure 1).

GFNMS covers an area of 3,295 square miles adjacent to a 300-mile stretch of the northern and central California coastline. Designated in 1981, GFNMS expanded to its current extent in

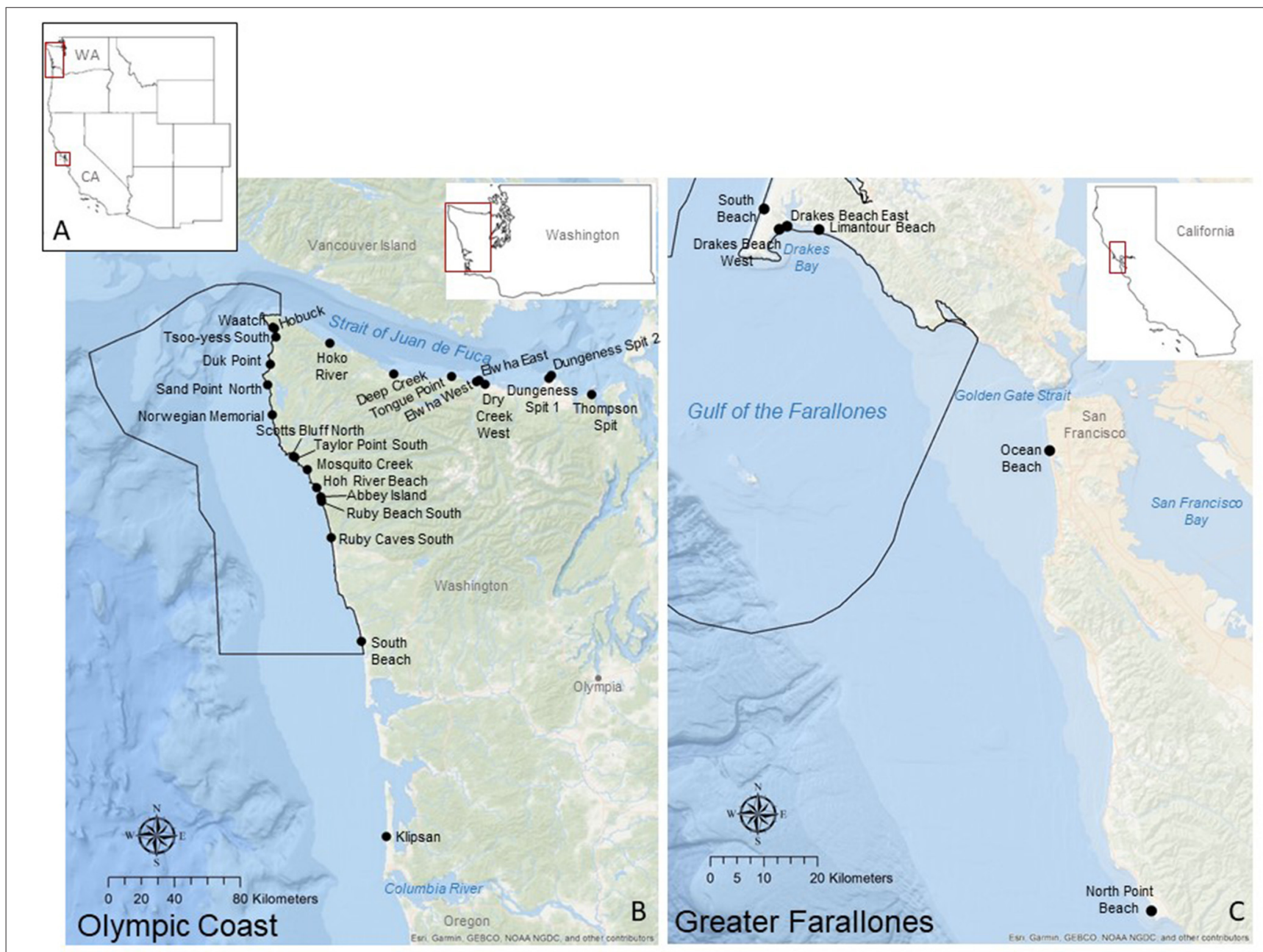

FIGURE 1 | Location of the Olympic Coast National Marine Sanctuary, Washington, and Greater Farallones National Marine Sanctuary, California in relation to one another along the west coast of the United States (A) Location of marine debris shoreline monitoring sites (closed circles) in Olympic Coast National Marine Sanctuary, Washington (B) and Greater Farallones National Marine Sanctuary, California (C). Where possible, portions of the sanctuaries' boundaries are indicated by black lines. 
2015. The GFNMS coastline includes a variety of broad sandy beaches, rocky cliffs, open bays (e.g., Drakes Bay) and enclosed bays or estuaries (e.g., Bolinas Lagoon) (GFNMS, 2014). The GFNMS hosts at least 25 threatened or endangered species (Greater Farallones NationalMarine Sanctuary (GFNMS), 2017) and extensive tourism, recreation, shipping, and commercial and recreational fishing activity, and is influenced by the San Francisco Bay outflow through the Golden Gate strait. The San Francisco Bay is the largest estuary on the U.S. West Coast and is currently home to a population of more than 7 million people. North of the Golden Gate strait, the coastline is more remote and is home to the Golden Gate National Recreation Area, Point Reyes National Seashore, and smaller coastal communities (e.g., Bodega Bay). The GFNMS experienced over three million person-days (a single individual doing an activity for any portion of a day) of recreational activity in 2011 (Leeworthy et al., 2015).

The OCNMS covers an area of 3,188 square miles adjacent to the Olympic Peninsula on the outer coast of Washington state. Designated in 1994, the OCNMS is home to 29 marine mammal species (eight of which are threatened or endangered) and 90 different seabird species (Olympic Coast National Marine Sanctuary (OCNMS), 2011). The outer coast of Washington is remote and largely undeveloped. Fifty-two miles of the OCNMS coastline is Olympic National Park designated wilderness. The OCNMS coastline is characterized by steep rocky headlands, sandy pocket beaches, and larger sandy and mixed rock/cobble beaches (Olympic Coast National Marine Sanctuary (OCNMS), 2011). The region has extensive recreational and commercial fishing activity. In 2016 there were over one million recreational fishing trips in Washington State and the seafood industry generated $\$ 2$ billion in personal income (National Marine Fisheries Service (NMFS), 2018).

The GFNMS and OCNMS coastlines are adjacent to the eastern boundary California Current system, which is characterized by wind-driven upwelling in the spring and early summer months (April to June; García-Reyes and Largier, 2012). Within the GFNMS, upwelling can be widespread or localized at upwelling centers (e.g., Point Arena; GFNMS, 2014). This upwelling of nutrient-rich deep water supports one of the most biologically productive areas of the world. The winter months (November to mid-February) in OCNMS are characterized by strong downwelling winds from the south, which also forces northward transport of the Columbia River discharge into sanctuary waters (Pirhalla et al., 2009).

\section{Marine Debris Monitoring and Assessment Project (MDMAP) Shoreline Monitoring Protocol}

The MDMAP includes two shoreline survey types, standing stock and accumulation. The standing stock survey protocol was developed as a rapid quantitative assessment of debris concentration at a shoreline site whereas the accumulation survey accommodates beach cleanup activity and provides an estimate of the flux, or accumulation rate, of debris onto a shoreline site (Lippiatt et al., 2013). Debris recorded during MDMAP surveys is at least $2.5 \mathrm{~cm}$ in any dimension. Survey sites presented here were designated as either standing stock (GFNMS) or accumulation (OCNMS and GFNMS). Surveyors completed a shoreline site characterization for each 100-meter long site. MDMAP shoreline site selection criteria provided in Lippiatt et al. (2013) include: sandy beach or pebble substrate, year-round access, no breakwaters or other structures that may affect coastal circulation, and no known regular (e.g., monthly) cleanup activity. MDMAP surveys should occur every 28 days (+/- 3 days) and as close to low tide as possible.

The survey protocols summarized here are described in detail in Lippiatt et al. (2013). For the MDMAP standing stock surveys, the 100-meter site is divided into 20 five-meter length transects that extend from the waters' edge to the back barrier of the shoreline (i.e., the first change in substrate). Four replicate transects are randomly selected prior to each survey event. Surveyors identify and record debris items within the four transects, but do not remove debris from the shoreline site. During accumulation surveys, debris is identified and removed from the entire 100-m site (e.g., no replicate transects).

Surveyors record debris items according to material type (e.g., plastic, metal, glass, rubber, processed lumber, cloth/fabric, and other/unclassifiable) and one of 46 standard item types (e.g., plastic fragments, plastic food wrappers, glass beverage bottles, and rubber gloves, etc.) listed on the MDMAP debris datasheet (see https://marinedebris.noaa.gov/mdmap-protocoldocuments-and-field-datasheets). Each material type includes fields for item fragments and "other" items not listed on the datasheet. Items are recorded under "unclassifiable" when not represented by other material types (i.e., leather and wax). In March 2013, the MDMAP database was updated to allow users to add custom debris items to their debris datasheet, as a subcategory under a designated standard material and item type. These are often debris items unique to a given locale or o particular local interest, whose regular occurrence indicated a need to inventory (e.g., plastic shotgun wads or oyster farming debris at GFNMS).

Safety protocols are provided in the MDMAP training materials (Lippiatt et al., 2013; see https://marinedebris.noaa.gov/ mdmap-tutorials). Monitoring coordinators from each sanctuary provided hard copies of these protocols and/or conducted in-person safety briefings for first-time volunteers using this information. In addition, annual site visits by each sanctuary coordinator were made for volunteer training review and updates to site characterization and survey datasheets. Ongoing communications with volunteers emphasized consistency of methodology and accurate data collection.

\section{Implementation of MDMAP in Greater Farallones National Marine Sanctuary}

GFNMS participants conducted monthly MDMAP surveys at four standing stock sites from July 2012 to June 2018, and two accumulation sites from June 2015 to June 2018 (Figure 1). The six sites were on lands managed by the National Park Service or California State Parks within Marin, San Francisco, and San Mateo counties. The accumulation survey sites were added later to facilitate additional community engagement and beach cleanup. GFNMS staff identified site locations according 
to MDMAP site selection criteria: (1) year-round beach access and space to accommodate a $100 \mathrm{~m}$ long site; (2) sand or pebble substrate; (3) away from management zones (e.g., endangered species conservation zones, enclosures, restoration areas); (4) no disruptions to nearshore circulation such as breakwaters or jetties; (5) no regular monthly clean-up activities, and; (6) manager/landowner permission (Lippiatt et al., 2013). Additional criteria for standing stock surveys required sites to be established in remote areas with very low or no public use and away from outflows such as drainage pipes, rivers or streams. Accumulation survey sites did not require any specific distance from outflows or human access points. Salient characteristics of each site are provided in Supplementary Table 1.

Based on volunteer feedback, GFNMS modified the layout (not the content) of the debris survey datasheets to increase ease of use when surveying in the field, but followed all other aspects of the published MDMAP protocols. GFNMS added two custom items to the standard MDMAP debris datasheet: plastic shotgun shells or wads (plastic barrier that sits inside the shell and separates the shot pellets from the gunpowder; added in May 2014) and plastic oyster farm debris (i.e., mesh bags and rack tubing, added in March 2013). In some instances, prior to addition of custom items, these items were listed in the notes section of the datasheet when they were recorded as "plasticother" items. For those surveys, the items were retroactively added to the appropriate custom item category, but in general, custom item counts should be considered an underestimate for the surveys prior to when they were officially added to the GFNMS datasheet.

For standing stock surveys, GFNMS staff (trained by MDP staff serving as MDMAP project leads) recruited and trained participants. Teams of two participants were assigned to a shoreline site and given a survey schedule. The GFNMS project lead joined one survey team every month to ensure that MDMAP protocols were followed. Only two of the original eight participants dropped out of the program (and were backfilled) over the duration of the project. In most cases, participants transcribed data from paper datasheets into the MDMAP database and mailed hard copies of paper survey forms to GFNMS staff for review. In other instances the GFNMS staff entered survey data to the MDMAP database directly. For accumulation surveys, GFNMS staff recruited high school and community groups on a rotating basis. Standing stock surveys usually had two participants per survey whereas accumulation surveys had an average of 3.8 participants per survey.

\section{Implementation of MDMAP in Olympic Coast National Marine Sanctuary}

Criteria from MDMAP (above, Lippiatt et al., 2013) were used to select 26 accumulation survey sites in OCNMS, nine on the Strait of Juan de Fuca and 17 on the outer coast (Figure 1), specifically selecting sites that would minimize the influence of shoresourced debris, be spatially separated from outflow sources such as drainage pipes and waterways, and relatively removed from recreational use. Preference was given for shoreline segments with relatively low public usage (not directly adjacent to parking or an access trail), little evidence of debris from day use (picnic debris), and few obstructions to nearshore circulation (e.g., breakwater and point of land) and ideally in areas with high rates of deposition. Sites were established between May 2012 and August 2014 and were monitored between one (Hoh River Beach) and 82 (Norwegian Memorial) times during the study period which ended August 2019. Salient characteristics of each site are provided in Supplementary Table 1.

Similar to GFNMS, OCNMS modified the accumulation survey datasheet but otherwise followed the MDMAP survey protocols. At the outset, OCNMS added 22 custom items to the standard material types. Like GFNMS, the predominant custom items included plastic oyster farm debris (e.g., yellow rope and spacer tubes; $39.7 \%$ of total custom items) and shot gun wads and shell casings ( $16.4 \%$ of total custom items) but also prevalent were firework pieces (29.1\% of total custom items).

OCNMS surveys had an average of 2.8 participants. Participants mailed or emailed scanned copies of paper survey forms to OCNMS staff for review and submission to the MDMAP database. Participants submitted a photo of all debris items after each survey, which OCNMS used to check for consistency in debris categorization. OCNMS staff periodically joined field surveys, and regularly addressed participant questions about the survey methodology. Participant retention was a challenge for OCNMS given low population density along much of the coast with sites often located in remote areas requiring long hikes. Fifty-two volunteers received formal field and online training from OCNMS staff (who themselves were trained by MDP staff serving as MDMAP project leads), with seven participating for the duration of the program.

\section{Marine Debris Monitoring and Assessment Project (MDMAP) Data}

Sanctuary staff submitted survey data to the NOAA MDP via the MDMAP database (https://mdmap.orr.noaa.gov/login). Database users transcribe shoreline, sampling area, and landuse information from the MDMAP site characterization form to create a shoreline site in the database, and designate the site as either accumulation or standing stock. Similarly, survey data is submitted by transcribing field data from debris survey datasheets (replicate transects for standing stock are each submitted separately). Photos of the survey area and/or debris items can be uploaded for each survey. Shoreline sites and survey data are subject to a verification process for quality assurance by NOAA staff prior to becoming accessible to all database users (any member of the public can request access to the MDMAP database). Survey data is downloaded to a .csv file using the reporting feature of the database.

\section{Statistical Methods}

Generalized additive models (GAMs) were fitted ( $\mathrm{R} m g c v$ package, Wood, 2011) to debris counts by survey type: one set of models for accumulation surveys and another set for standing stock. Response variables in each set of models included total debris item count broken down by material type (plastic, metal, glass, rubber, lumber, fabric, and unclassified), and plastic item count broken down by category (balloons, fishing, fragments, 
single use, smoking, and other). Models employed a negativebinomial response structure (log-link) to handle overdispersion present in item counts.

Inference on trend in survey item counts for plastic items and fishing-related items over time was conducted following Piepho and Ogutu (2002) for replicated data with unstructured covariance, with the linear version of the model taking the form as per Equation (1) (site ID was dropped from standing stock models due to a zero variance component):

$$
\begin{array}{r}
\ln \left(y_{i j k}\right)=\beta_{0}+\beta_{1} w_{j}+\beta_{2, \ldots} x_{2, \ldots}+b_{j}+a_{i}+w_{j} t_{i}+c_{i j}+e_{i j k}(1) \\
\left(i=1, \ldots, m_{\mathrm{a}} ; j=1, \ldots, m_{\mathrm{b}} ; k=1, \ldots, m\right),
\end{array}
$$

where

$$
\begin{aligned}
& m_{\mathrm{a}}=\text { number of sites } \\
& m_{\mathrm{b}}=\text { number of consecutive years } \\
& m=\text { number of measurements taken within a site and year } \\
& y_{i j k}=\text { debris item count } \\
& \beta_{0}=\text { intercept } \\
& w_{j}=\text { fixed effect representing jth survey year (continuous) } \\
& \beta_{1}=\text { slope of linear trend } \\
& x_{2, \ldots}=\text { additional fixed effects and interactions } \\
& \beta_{2, \ldots}=\text { estimated coefficients of fixed effects } \\
& b_{j}=\text { random effect of jth year, } \sim \mathrm{N}\left(0, \sigma_{\mathrm{b}}^{2}\right) \\
& a_{i}=\text { random intercept of ith site, } \sim \mathrm{N}\left(0, \sigma_{\mathrm{a}}^{2}\right) \\
& t_{i}=\text { random slope of ith site, } \sim \mathrm{N}\left(0, \sigma_{\mathrm{t}}^{2}\right) \\
& c_{i j}=\text { random effect of site by year, } \sim \mathrm{N}\left(0, \sigma_{\mathrm{c}}^{2}\right) \\
& e_{i j k}=\text { unexplained error, } \sim \mathrm{N}\left(0, \sigma^{2}\right) .
\end{aligned}
$$

In addition, non-independence of counts among material types recorded on the same survey was accounted for by including survey ID as a random effect.

Each model included beach width $(\mathrm{m})$ and number of persons assisting as smooth terms fit with sufficiently high maximum allowable degrees of freedom to be able to detect any non-linear patterns present in survey effort. Time spent surveying was not considered as an effort variable as participants are instructed to perform a census of debris within each transect regardless of the time it takes to complete. The accumulation survey models included a term for the number of days since a prior survey had been conducted to account for the effect of past item removal on current survey counts. To handle observations with no prior survey at a site, a dummy variable (Is Initial) was constructed to identify whether an observation came from the initial survey at a site, allowing the models to estimate the effect of days since a prior survey only when a prior survey had occurred. To reduce the disproportionate influence of very few data points with multiple years between surveys, any prior survey dates of $>1$ year were treated as the initial survey at a site for estimation purposes.

Potential fixed effects considered for each model included sanctuary (GFNMS and OCNMS), calendar season (winter: DecFeb; spring: Mar-May; summer: Jun-Aug; fall: Sep-Nov), numeric survey year to quantify trend, and all associated interactions. Site specific covariates considered for inclusion were tidal range, nearest river distance, nearest town distance, tidal distance, beach aspect, beach access (pedestrian, vehicular, and isolated), and whether or not a site had river or creek input (the latter three were only considered for accumulation survey models as levels were too sparse to include in standing stock models). All fixed effects and interactions were selected according to the lowest Bayesian Information Criteria (BIC) among candidate models with all combinations of up to three-way interactions of categorical variables and subsequent lower order terms fit by maximum likelihood, with the final selected model fit using restricted maximum likelihood. This same technique was used to determine whether continuous covariates should be included as smooth or linear terms. Smooth terms were fit iteratively increasing the maximum basis dimension $(k)$ until it was evident there were minimal gains in effective degrees of freedom. Significance was set at alpha $=0.05$.

General linear hypothesis tests of trend in specific material types over time and seasonal variation in item counts were conducted using the R multcomp package (Hothorn et al., 2008), with confidence intervals and $p$-values adjusted for multiple comparisons based on the joint normal distribution of the linear function.

\section{RESULTS}

\section{Descriptive Statistics}

A total of 2,167 transects were surveyed across 32 coastal sites in the two sanctuaries (Greater Farallones National Marine Sanctuary [GFNMS]: 1,162; Olympic Coast National Marine Sanctuary [OCNMS]: 1,005). The number of participants for standing stock surveys ranged from one to four (mean: 2) while for accumulation surveys, the number of participants ranged from one to 35 (mean: 2.8). Transects varied in width (distance from water's edge to the back barrier) from 10 to $109 \mathrm{~m}$ in GFNMS (median: $40 \mathrm{~m}$; mean: $45 \mathrm{~m}$ ) and $2 \mathrm{~m}$ to $550 \mathrm{~m}$ in OCNMS (median: $60 \mathrm{~m}$; mean: $79.3 \mathrm{~m}$ ). The greatest amount of debris occurred in GFNMS, with significant variation among sites. It should be noted that the two accumulation sites in GFNMS were public access beaches, having parking lots and with frequent year-round visitation vs. the more remote standing stock site locations which were either not readily accessible by the public, or located further $(\geq 400 \mathrm{~m})$ from the main beach entrance.

Items per transect, scaled to $100 \mathrm{~m}$ length parallel to the shoreline for standing stock surveys, ranged from 0 to 1,484 , yielding an average count of 203 items per $100 \mathrm{~m}$ length of shoreline (median: 100) in GFNMS and 60.9 items per $100 \mathrm{~m}$ length of shoreline (median: 30) in OCNMS. Approximately $91 \%$ of the 27,985 debris items in GFNMS and $86 \%$ of the 61,194 debris items in OCNMS were plastic, while the second most prevalent item was lumber (GFNMS: 5.2\%, OCNMS: $8.9 \%$ ). Identifiable plastic objects were present, but the vast majority of plastic items were fragments of indeterminate origin (GFNMS: 73.2\%, OCNMS: $63.2 \%$ ), including hard, foam, and film.

\section{Model Results \\ Accumulation Surveys}

The final model selected to explain variation in total debris count of all material types (plastic, metal, glass, rubber, lumber, fabric, unclassified) from accumulation surveys (GFNMS, OCNMS) included the parametric terms debris type, season, sanctuary, 
TABLE 1 | Summary of the final negative binomial model (log link function) for total debris item count found during accumulation surveys in Greater Farallones (GFNMS) and Olympic Coast (OCNMS) National Marine Sanctuaries.

\begin{tabular}{|c|c|c|c|}
\hline Parametric terms & df & Chi-square & $P$-value \\
\hline Type & 6 & 452.4 & $<0.0001$ \\
\hline Season & 3 & 12.4 & 0.0061 \\
\hline Sanctuary & 1 & 10.5 & 0.0012 \\
\hline Survey year & 1 & 0.07 & 0.79 \\
\hline Is initial & 1 & 1.8 & 0.19 \\
\hline Tidal range & 1 & 12.6 & 0.0004 \\
\hline River/creek input & 1 & 3.9 & 0.05 \\
\hline Access & 2 & 4.9 & 0.085 \\
\hline Type:Season & 18 & 161.9 & $<0.0001$ \\
\hline Type:Sanctuary & 6 & 51.0 & $<0.0001$ \\
\hline Season:Sanctuary & 3 & 13.3 & 0.004 \\
\hline Sanctuary:Survey year & 1 & 0.3 & 0.61 \\
\hline Type:Survey year & 6 & 12.1 & 0.061 \\
\hline Is initial:Days since prior & 1 & 8.7 & 0.0032 \\
\hline Type:Sanctuary:Survey year & 6 & 13.6 & 0.035 \\
\hline Smooth terms & edf & Chi-square & $P$-value \\
\hline s(Nearest river distance) & 2.06 & 7.5 & 0.24 \\
\hline s(Width) & 1.08 & 0.3 & 0.67 \\
\hline s(Persons assisting) & 2.7 & 14.9 & 0.0018 \\
\hline s(Survey year:Site) & 10.7 & 1688.4 & 0.032 \\
\hline s(Site) & 13.2 & 3227.9 & 0.0007 \\
\hline s(Site:Year) & 45.0 & 415.2 & 0.0003 \\
\hline s(Year) & $2.4 \mathrm{e}-06$ & 0 & 0.46 \\
\hline s(Survey ID) & 493 & 1226.6 & $<0.0001$ \\
\hline
\end{tabular}

Type III Wald significance tests (approximate Chi-square) of parametric and smooth terms included in the final model are presented. Interaction terms are separated by a colon. edf denotes effective degrees of freedom for smooth terms.

survey year, tidal range, river/creek input, beach access type, and the interaction terms of debris type $\mathrm{x}$ season, debris type $\mathrm{x}$ sanctuary, season $\mathrm{x}$ sanctuary, sanctuary $\mathrm{x}$ survey year, debris type $\mathrm{x}$ survey year, number of days since prior survey, and debris type x sanctuary x survey year (Table 1, Supplementary Table 2). In addition, the terms nearest river, beach width, number of persons assisting, and random effects as referenced in the Piepho and Ogutu (2002) model description above were included as smooths ( $\mathrm{df}=6,829 ; 82.6 \%$ deviance explained) (Table 1, Supplementary Table 2). When considering plastic item count only (balloons, fishing, fragments, single use, smoking, and other), the selected model was the same as for the all material types above, with the exception that the three-way interaction of debris type $\mathrm{x}$ sanctuary $\mathrm{x}$ survey year was dropped $(\mathrm{df}=5,588$; $84.9 \%$ deviance explained) (Supplementary Tables 3, 4). Model predicted counts of total debris per $100 \mathrm{~m}$ length of shoreline were dominated by plastic, specifically fragments, with GFNMS having more debris than OCNMS for accumulation surveys (Supplementary Figures 1, 2).
TABLE 2 | Summary of the final negative binomial model (log link function) for total marine debris item counts found during standing stock surveys in Greater Farallones National Marine Sanctuary.

\begin{tabular}{|c|c|c|c|}
\hline Parametric terms & df & Chi-square & $P$-value \\
\hline Type & 6 & 1091.8 & $<0.0001$ \\
\hline Season & 3 & 11.6 & 0.0089 \\
\hline Nearest town distance & 1 & 5.7 & 0.017 \\
\hline Nearest river distance & 1 & 8.0 & 0.0046 \\
\hline Type:Season & 18 & 52.4 & $<0.0001$ \\
\hline Smooth terms & edf & Chi-square & $P$-value \\
\hline s(Survey year) & 1.0 & 0.08 & 0.77 \\
\hline s(Survey year:Type = Fabric) & 1.8 & 3.2 & 0.12 \\
\hline s(Survey year:Type = Glass) & $4.1 e-08$ & 0 & 1.0 \\
\hline s(Survey year:Type = Lumber) & 2.2 & 7.6 & 0.018 \\
\hline s(Survey year:Type = Metal) & $3.8 e-07$ & 0 & 0.79 \\
\hline s(Survey year:Type = Plastic) & 3.1 & 93.4 & 0.007 \\
\hline s(Survey year:Type = Rubber) & $1.2 \mathrm{e}-05$ & 0 & 0.43 \\
\hline s(Survey year:Type = Unclassified) & 2.8 & 11.2 & 0.003 \\
\hline s(Beach width) & 1.7 & 21.2 & $<0.0001$ \\
\hline s(Persons assisting) & 1 & 6.8 & 0.009 \\
\hline s(Survey year:Site) & $1.8 e-06$ & 0 & 0.52 \\
\hline s(Site:Year) & 7.6 & 164.6 & 0.092 \\
\hline s(Year) & 4.2 & 826.2 & 0.001 \\
\hline s(Survey ID) & 200 & 1106.6 & $<0.0001$ \\
\hline
\end{tabular}

Type III Wald significance tests (approximate Chi-square) of parametric and smooth terms included in the final model are presented. Interaction terms are separated by a colon. edf denotes effective degrees of freedom for smooth terms.

\section{Standing Stock Surveys}

For standing stock surveys (GFNMS), the selected model for total debris item count included the parametric terms debris type, season, nearest town, nearest river, and debris type $\mathrm{x}$ season with smooth terms survey year, debris type $\mathrm{x}$ survey year, beach width, number of persons assisting, and random effects as referenced above ( $\mathrm{df}=7,458 ; 86.5 \%$ deviance explained) (Table 2, Supplementary Table 5). The selected model for plastic item count only included the parametric terms debris type, season, nearest river, and debris type $\mathrm{x}$ season and the smooth terms survey year, debris type $\mathrm{x}$ survey year, nearest town, beach width, number of persons assisting, and random effects ( $\mathrm{df}=$ 6,347; 76.7\% deviance explained) (Supplementary Tables 6, 7).

\section{Trends and Seasonality}

Model results from both accumulation (2015-2018) and standing stock (2012-2018) surveys indicate evidence of annual trends in plastic item counts over the survey period in GFNMS (Table 3). This trend was negatively linear for accumulation surveys $(p=$ 0.037) (Table 3, Figure 2), however, the longer time series of observations in the standing stock survey for GFNMS allowed a non-linear relationship to be detected with maximum expected plastic item counts occurring between 2014 and 2016 ( $p=0.007)$ (Figure 3). Expected plastic item counts on accumulation surveys 
TABLE 3 | General linear hypothesis tests of linear trend in counts of total plastic items and fishing related plastic items in Greater Farallones (GFNMS) and Olympic Coast (OCNMS) National Marine Sanctuaries from accumulation survey data.

\begin{tabular}{|c|c|c|c|c|c|}
\hline Debris Category & Sanctuary & $\begin{array}{l}\text { Deviance } \\
\text { Explained }\end{array}$ & Linear Trend & $\%$ Change & $\boldsymbol{P}$ \\
\hline Plastic & Greater Farallones & $82.6 \%$ & Neg & $-44.2 \%(-67.9,-2.8) \%$ & 0.037 \\
\hline \multirow[t]{2}{*}{ Fishing gear } & Greater Farallones & $84.9 \%$ & Neg & $-43.6 \%(-61.7,-17.0) \%$ & 0.002 \\
\hline & Olympic Coast & & Neg & $-9.5 \%(-18.4,0.4) \%$ & 0.063 \\
\hline
\end{tabular}

Total deviance explained is displayed for the respective GAM fit containing the comparisons of interest. Annual percent changes (95\% confidence intervals) are model estimated averages over the length of the survey period within each sanctuary (GFNMS: 2015-2018; OCNMS 2012-2019). P-values are adjusted for multiple comparisons.

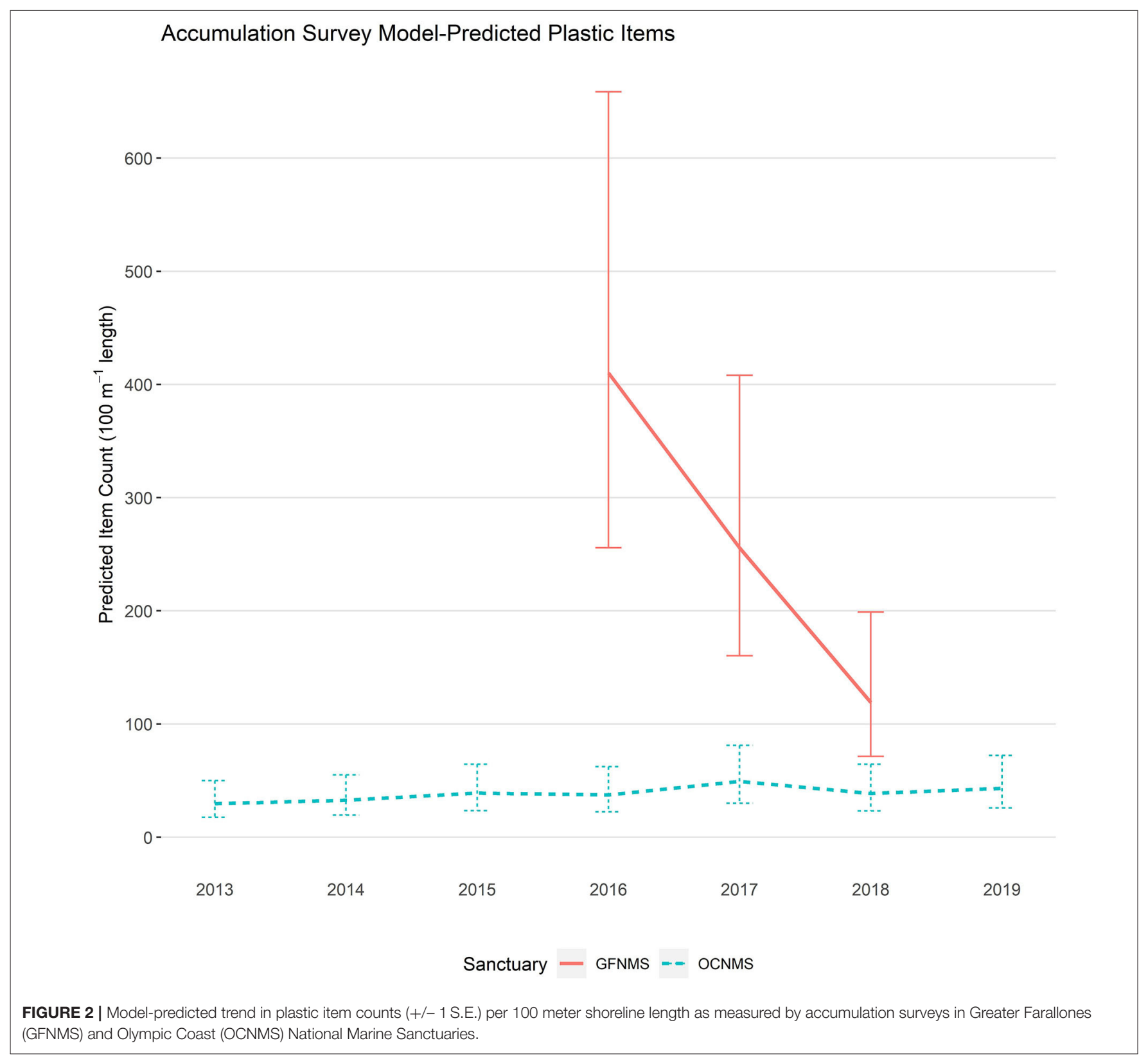




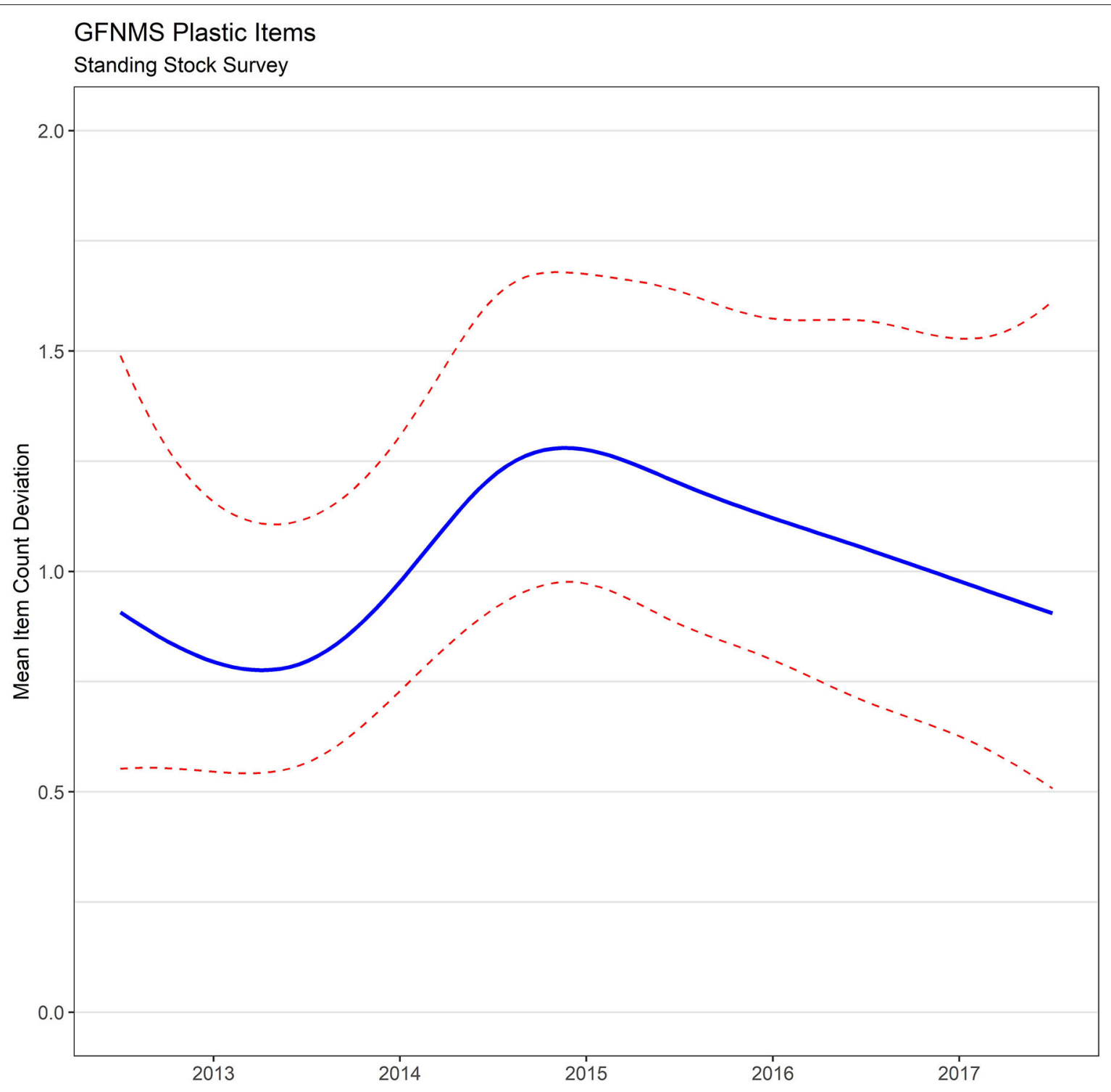

FIGURE 3 | Model-estimated smooth trend in plastic item counts as measured by standing stock surveys in Greater Farallones National Marine Sanctuary (GFNMS). Solid blue-line represents the expected deviation from the average count across the survey period (e.g., 1.2 represents an expected count $20 \%$ higher than average). Dashed red lines show $295 \%$ confidence bands.

exhibited a $44.2 \%$ annual decrease (95\% CI: $-67.9 \%,-2.8 \%)$ over years 2015-2018 ( $p=0.037$ ) (Table 3). Likewise, expected counts of fishing related items saw a $43.6 \%$ annual decrease $(95 \% \mathrm{CI}$ : $-61.7 \%,-17.0 \%)$ over this same period $(p=0.002)$ (Table 3 ). In contrast, no significant trends were detected in OCNMS accumulation surveys for either plastic items $(p=0.32)$ or fishing related items $(p=0.063)$ over the survey period (2012-2019) (Table 3).

Calendar season showed a clear association with expected total debris item count (accumulation: $p=0.006$; standing stock: $p=$ 0.009) (Tables 1, 2) as well as for expected counts of plastic items from accumulation surveys $(p=0.024)$, but this relationship was less evident for standing stock survey data $(p=0.081)$ (Supplementary Tables 3, 6). For OCNMS, plastic item counts were higher in winter vs. all other seasons but only significant when compared to summer and fall (Table 4, Figure 4). No other season comparisons were significant. Winter also exhibited higher counts of plastic items in GFNMS compared to other seasons throughout the longer time series of standing stock surveys, with winter and spring exhibiting significantly higher counts than both summer and fall (Table 4, Figure 4).

\section{Survey Effort Variables}

The models also provided the ability to obtain an estimate of how the length of time between accumulation surveys at a given site correlates with the expected total debris item count on a current survey. It was observed that this association was roughly loglinear over a 365 day period, with an expected $0.34 \%$ increase in 
TABLE 4 | Seasonal pairwise comparisons of estimated plastic item counts within and between Greater Farallones (GFNMS) and Olympic Coast (OCNMS) National Marine Sanctuaries

\begin{tabular}{|c|c|c|c|c|}
\hline Accumulation: Plastic Items & Estimate & Lower Cl & Upper Cl & $P$ \\
\hline \multicolumn{5}{|l|}{ Greater Farallones } \\
\hline Fall-Winter & 2.0 & 0.7 & 5.4 & 0.39 \\
\hline Fall-Summer & 1.5 & 0.6 & 3.8 & 0.81 \\
\hline Fall-Spring & 1.4 & 0.5 & 3.8 & 0.95 \\
\hline Spring-Winter & 1.4 & 0.5 & 3.7 & 0.96 \\
\hline Summer-Winter & 1.3 & 0.5 & 3.3 & 0.99 \\
\hline Spring-Summer & 1.1 & 0.4 & 2.7 & 1.0 \\
\hline \multicolumn{5}{|l|}{ Olympic Coast } \\
\hline Winter-Summer & 1.9 & 1.3 & 2.6 & $<0.0001$ \\
\hline Winter-Fall & 1.7 & 1.2 & 2.4 & 0.0002 \\
\hline Spring-Summer & 1.4 & 1.0 & 1.9 & 0.06 \\
\hline Winter-Spring & 1.4 & 1.0 & 1.9 & 0.09 \\
\hline Spring-Fall & 1.2 & 0.9 & 1.7 & 0.52 \\
\hline Fall-Summer & 1.1 & 0.8 & 1.5 & 0.98 \\
\hline \multicolumn{5}{|l|}{ Greater Farallones-Olympic Coast } \\
\hline Fall & 18.2 & 2.5 & 131.4 & 0.0004 \\
\hline Summer & 13.0 & 1.8 & 91.7 & 0.002 \\
\hline Spring & 10.3 & 1.5 & 71.9 & 0.007 \\
\hline Winter & 5.4 & 0.8 & 38.8 & 0.15 \\
\hline Standing Stock: Plastic Items & Estimate & Lower $\mathbf{C l}$ & Upper Cl & $P$ \\
\hline \multicolumn{5}{|l|}{ Greater Farallones } \\
\hline Winter-Fall & 2.5 & 1.6 & 4 & $<0.0001$ \\
\hline Spring-Fall & 2.3 & 1.5 & 3.6 & $<0.0001$ \\
\hline Winter-Summer & 2 & 1.3 & 3 & 0.0002 \\
\hline Spring-Summer & 1.8 & 1.2 & 2.7 & 0.0009 \\
\hline Summer-Fall & 1.3 & 0.9 & 1.9 & 0.40 \\
\hline Winter-Spring & 1.1 & 0.7 & 1.7 & 0.92 \\
\hline
\end{tabular}

Estimates are multiplicative factors (i.e., $2.0=2 \times$ expected debris count) with corresponding lower and upper 95\% confidence intervals (Cl). P-values are adjusted for multiple comparisons.

total debris item count (Table $1, p=0.003$ ) for each additional day between surveys and a $0.29 \%$ increase in expected plastic item count (Supplementary Table 2, $p=0.011$ ). These estimates can potentially be used to adjust debris load estimates from future accumulation surveys back to a state as if debris were never removed previously by multiplying by the result of Equation (2):

$$
\exp \left\{0.003414\left(d_{t}-d_{p}\right)\right\}
$$

where

$d_{t}=$ days for complete turnover to occur

$d_{p}=$ days since prior removal survey $<d_{t}$ for $d_{p}>3$ and $d_{t}<365$.

Beach width (distance from water's edge to the back of the shoreline) was also associated with expected total debris item count. For accumulation surveys, the relationship appeared to be roughly linear but not significant for the all material types (effective degrees of freedom $=1.08, p=0.67$, Table 1 ) whereas for plastic items only, expected counts increased roughly linearly with beach width (edf $=1.002 ; p=0.013$ )
(Supplementary Table 3). In standing stock surveys (GFNMS), however, expected counts for total debris items and those of only plastic items were observed to increase non-linearly with beach width, and these relationships were significant (total debris: edf $=1.7, p<0.0001$; plastic items: edf $=2.0, p<0.0001)$ (Table 2, Supplementary Table 6, respectively, Figure 5). Fitted models indicate a steady increase in expected total debris item count in beaches up to $60-70 \mathrm{~m}$ in width, with expected total debris counts (especially of plastic items) increasing at an increased rate in beaches wider than this threshold (Figure 5).

Similarly, in both standing stock and accumulations surveys, the number of persons assisting on a survey seems to have a modest positive relationship with the expected total debris item count up to a threshold of about four to five people, after which having additional people assist does not significantly increase expected total counts (accumulation: $p=0.002$; standing stock: $p=0.009$ ) (Figure 6).

\section{Site-Level Variables}

An examination of site-level covariates revealed evidence of a significant positive relationship between accumulation survey debris item counts and tidal range (vertical) (total debris: $p=0.0004$; plastic items: $p<0.0001$ ) (Table 1, Supplementary Table 3, respectively). Other potentially important environmental variables in predicting plastic loads as measured on accumulation surveys include beach access type (plastic items: $p=0.033$ ), whether river or creek input was present (total debris: $p=0.05$; plastic items: $p=0.025$ ), and distance of a site to the nearest river (plastic items: $p<0.0006$ ) (Table 1, Supplementary Table 3, respectively). Standing stock data indicated distance to the nearest river (total debris: $p=$ 0.005; plastic items: $p=0.003$ ) and distance to the nearest town (total debris: $p=0.017$; plastic items: $p=0.049$ ) were significant predictors (Table 2, Supplementary Table 6, respectively).

\section{DISCUSSION}

This study has shown that monitoring data can be used to estimate marine debris abundance and temporal trends, and identify drivers of debris loads on shorelines within two US National Marine Sanctuaries: Olympic Coast (OCNMS) and Greater Farallones (GFNMS). Similar to other shoreline monitoring studies worldwide, marine debris in the two sanctuaries was dominated by plastic items, in particular, plastic fragments (Derraik, 2002; Thiel et al., 2013; Hong et al., 2014; Hoellein et al., 2015; Schulz et al., 2015; Hardesty et al., 2017a,b; Nelms et al., 2017; Araujo et al., 2018; da Silva et al., 2018; Ko et al., 2018; Ryan et al., 2018; Ambrose et al., 2019).

Seasonal effects in both debris counts and composition of debris were apparent (OCNMS: accumulation; GFNMS: standing stock) and likely reflect patterns of coastal upwelling and downwelling in the region (Pirhalla et al., 2009; García-Reyes and Largier, 2012) where debris counts are highest in winter and spring (downwelling) vs. summer and fall and typically fall is greater than summer (OCNMS only). Ekman transport associated with downwelling leads to onshore movement of the surface mixed layer which can transport and deposit debris 


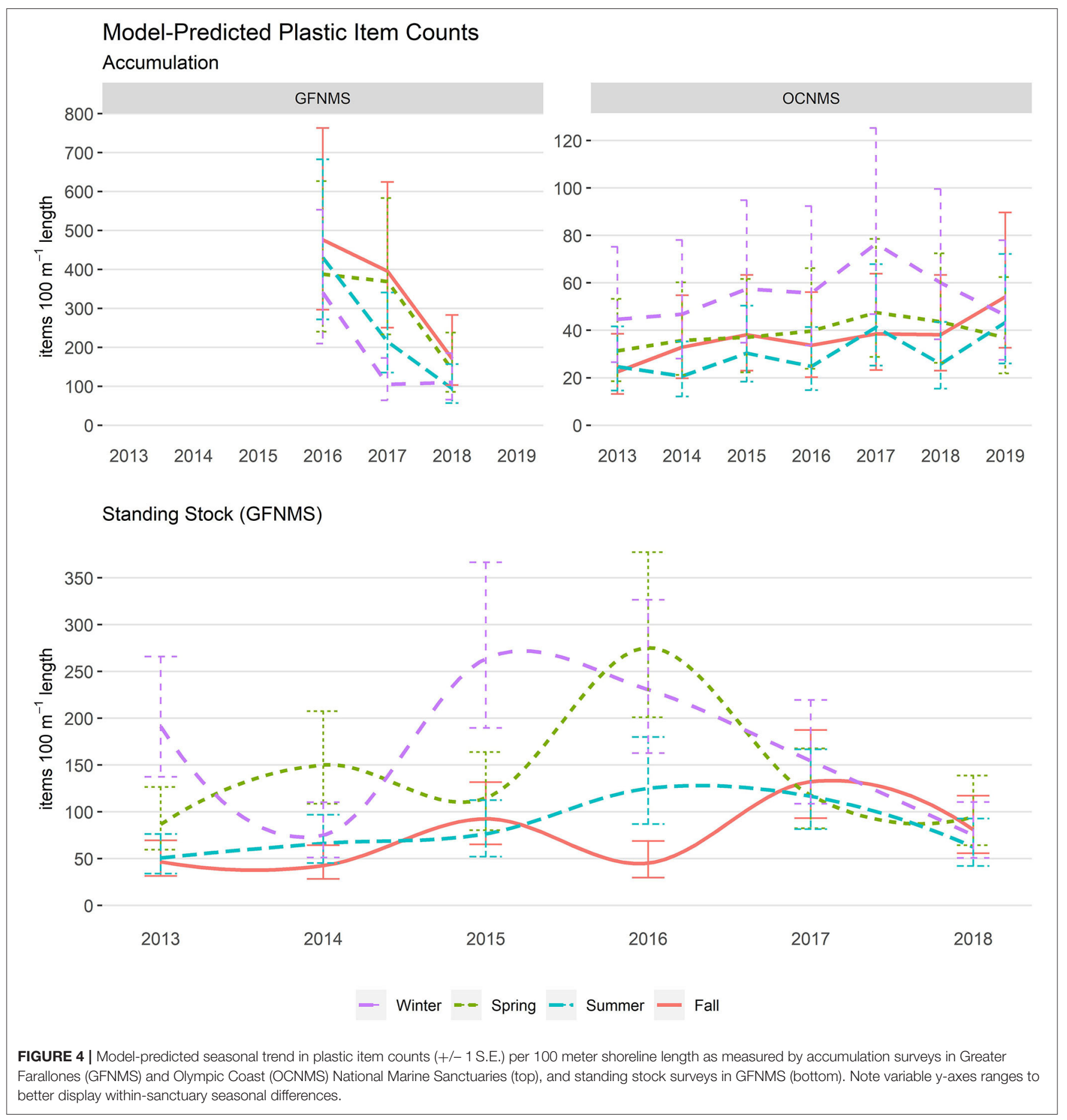

onto shorelines. Similar seasonal trends, presumably associated with downwelling, have previously been reported for general source and ocean-based indicator items surveyed in the Pacific Northwest (Oregon and Northern California: Ribic et al., 2012). Kako et al. (2018) documented gradual increases in marine debris abundance beginning in September through winter and into March over a 1-year period on shorelines near Newport,
Oregon which was attributed to coastal downwelling. Of note here, the storm season overlaps with the downwelling season, making it difficult to distinguish between the two variables in terms of changes in debris. Downwelling-associated patterns in marine debris were not obvious for the GFNMS accumulation data which could be a result of limited spatial replication $(n=$ 2) for this survey type. Further, one of the GFNMS accumulation 


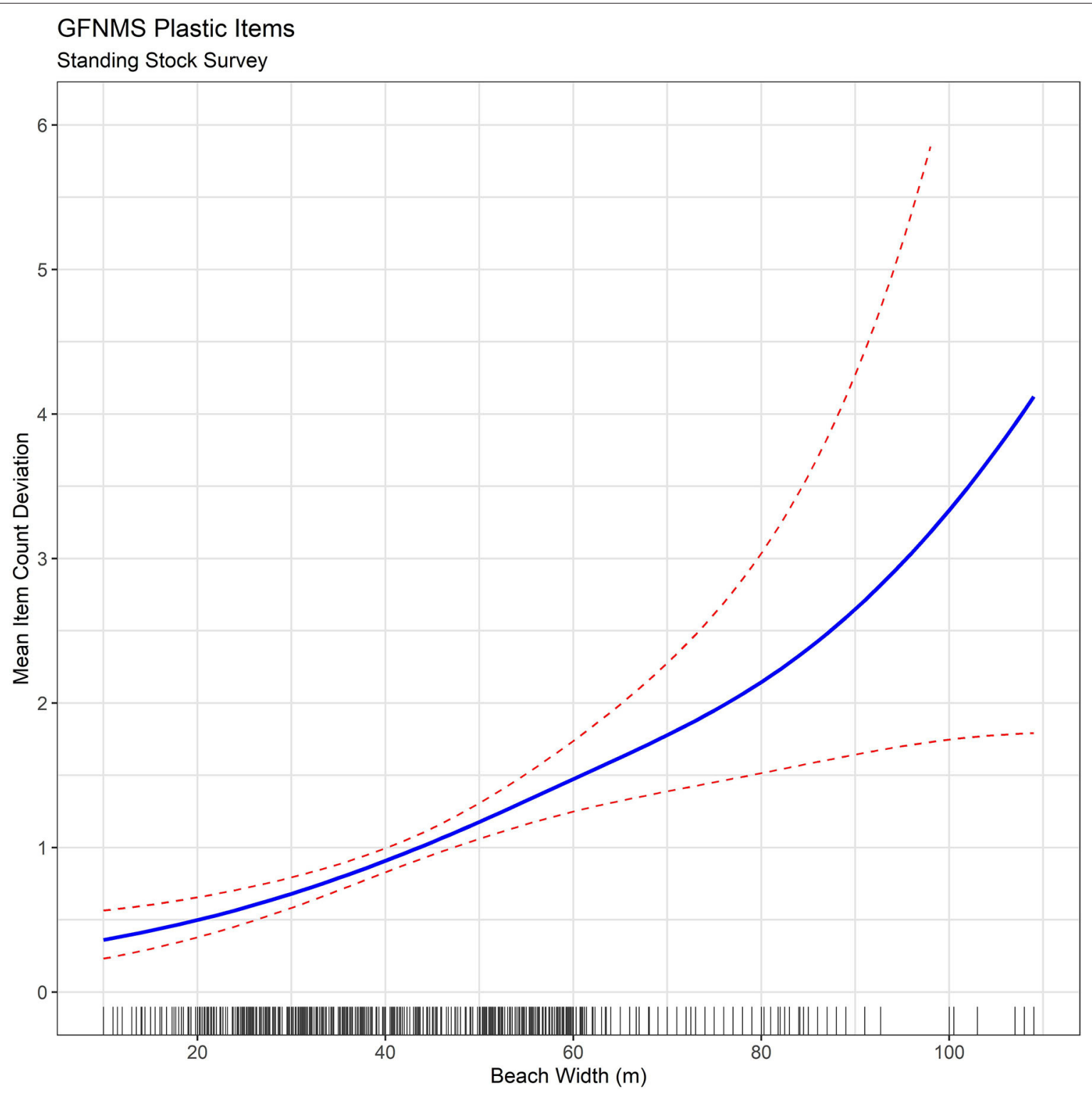

FIGURE 5 | Model-estimated effect of beach width on expected plastic item counts as measured by standing stock surveys in Greater Farallones National Marine Sanctuary (GFNMS). Solid blue-line represents the deviation from the expected plastic item count on a beach of average width (e.g., the average beach was roughly 45 meters wide; beaches 60 meters wide are expected to contain 50\% more plastic items). Dashed red lines show 95\% confidence bands. Black tick marks on the inner $x$-axis each represent a transect that was surveyed.

sites, Drakes Beach West, is located within an upwelling shadow at Drakes Bay (Wing et al., 1998). The retention of warmer surface water acts as a barrier for mixing (Graham and Largier, 1997) and upwelling is reduced which may inhibit offshore debris movement. Often these locations are contained within a curved coastline downstream from capes or headlands such as Drakes Bay. An analysis of storm events was attempted by GFNMS staff but significant differences between defined storm and non-storm events were not apparent (Bimrose et al., 2018). Comparatively speaking, GFNMS had higher debris counts vs. OCNMS overall and across all seasons.
Modeling resulted in variable temporal trends in marine debris both within and across the two sanctuaries, suggesting that estimating temporal patterns in marine debris counts is challenging at best. A significant and continuous decline in marine debris counts from 2016 to 2019 was predicted for the GFNMS accumulation surveys which is consistent with compliance by San Francisco Bay Region municipalities with required reductions in stormwater trash discharges according to Municipal Regional Stormwater National Pollutant Discharge Elimination System Permit Number CAS612008, Provision C.10 which requires permittees to reduce trash loads from municipal 


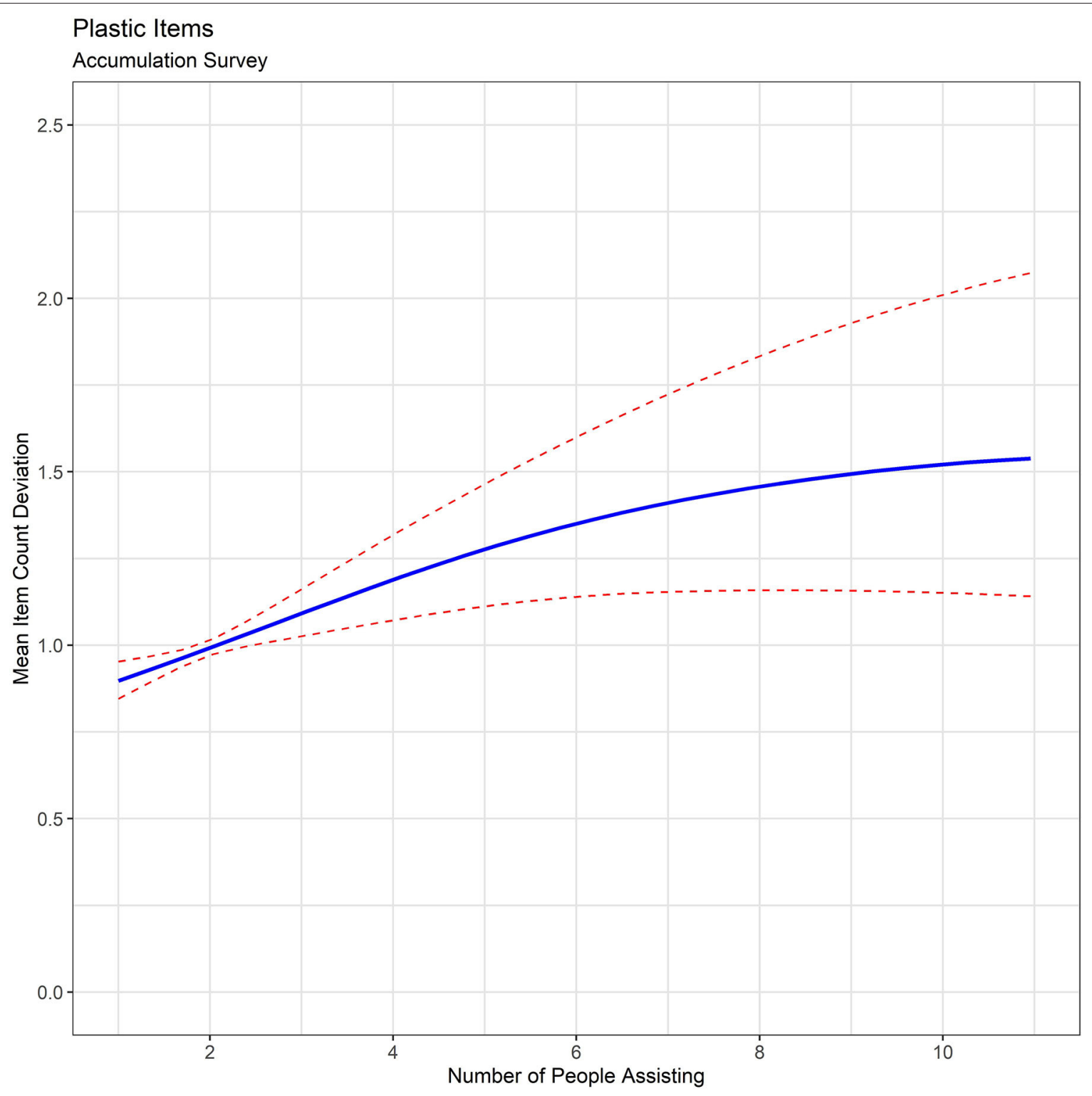

FIGURE 6 | Model-estimated effect of the number of persons assisting on expected plastic item counts as measured by accumulation surveys in Greater Farallones (GFNMS) and Olympic Coast (OCNMS) National Marine Sanctuaries. Solid blue-line represents the deviation from the expected plastic item count on a survey with the average number of participants (i.e., two). Dashed red lines show 95\% confidence bands. It appears counts increase in a roughly linear fashion between one and four participants, with this effect diminishing at higher numbers.

separate storm sewer systems by $40 \%$ by $2014,70 \%$ by $2017,80 \%$ by July 1,2019 , and $100 \%$ by 2022 . However, given both limited site (two) and temporal (4 years) replication, it is possible that one of the sites or years is creating bias. Examining the raw data reveals that one site (Drakes Beach West) experienced high debris counts initially, followed by a sudden drop in the span of 1 year. At Ocean Beach, debris counts continually increased over a 3year period, after which a sudden drop occurred back to year one values. Ocean Beach is subject to chronic erosion which is exacerbated during intense El Niño winter storms. The 2015-16 El Niño was particularly stormy, followed by an atypical La Niña event in which extended rainy periods in January and February 2017 resulted in record setting precipitation for San Francisco. This led to a narrowing of the marine debris survey area and subsequent beach nourishment possibly covered or displaced debris that might otherwise have been recorded. Hardesty et al. (2017b) suggested temporal and site bias as a possible mechanism for a modeled positive trend in debris loads for accumulation surveys along the west coast of the United States. In that analysis, several very high density sites were added to the dataset in the final period of sampling, despite no overall linear change in the raw data (Hardesty et al., 2017b). 
The non-linear trend in plastic item standing stock counts for GFNMS resulted from a large but temporary peak in debris observed in 2015, but no overall linear change was apparent. Ribic et al. (2012) also reported non-linear trends in the flux of debris indicator items along the North Pacific Coast (Oregon, Northern California) and Southern California (south of Point Conception) over a nearly 9-year period, largely driven by temporary peaks in debris or initially high debris loads that then declined over time, resulting in no overall linear tendency. General-source debris loads were elevated when it rained or stormed in the weeks before a survey (Ribic et al., 2012).

In contrast to GFNMS, no significant temporal trend in marine debris counts was detected for the OCNMS accumulation data, despite a longer temporal sequence and greater site replication in the dataset. Lack of temporal trend is not unusual among marine debris shoreline monitoring datasets worldwide, even at timescales greater than our study. Nelms et al. (2017) found no temporal trend in the overall abundance of debris across the United Kingdom over a 10-year period, although some significant increases in specific debris items were reported (e.g., plastic fragments, balloons, and fishing nets). Schulz et al. (2015) analyzed shoreline data from the southeastern coast of the North Sea and found that although short-term increases and decreases occurred, there was no general linear change in debris over a 25 -year period. Power analyses performed to determine trend detection thresholds for seafloor marine debris monitoring data collected via trawl revealed that distinguishing a $\leq 20 \%$ change over 5-10 years is unlikely without very large sample sizes (Moriarity et al., 2016). In fact, even with 90 sampling sites, there is just enough power to detect a $40-50 \%$ change over $10-$ 15 years (Moriarity et al., 2016). Lack of trend may also result from environmental variability within and among monitoring locations that affects transport, stranding, and resuspension including currents, tides, wind, and coastal topography which can mask temporal trends (Ryan et al., 2009; Schulz et al., 2013, 2015). Organized cleanup events at or near monitoring sites may also influence temporal trends. Less debris was found on North American Great Lakes beaches in summer when municipal beach cleaning activities were implemented (Hoellein et al., 2015; Vincent et al., 2017). Conversely, Santos et al. (2009) reported that regularly-cleaned beaches in northeast Brazil had smaller sized debris but no changes in overall abundance were observed. Annual clean up events associated with Earth Day and the International Coastal Cleanup as well as intermittent, locallyorganized removals do occur in both GFNMS and OCNMS at locations that either overlap or are in close proximity to the monitoring sites for these sanctuaries. However, it is difficult to track and control for these activities when estimating temporal trends from monitoring data.

We identified a sampling effect in terms of the number of people conducting a survey for both accumulation and standing stock surveys. As the number of individuals participating in a survey increased, the total expected debris counts increased linearly up to five participants, after which, having additional persons did not significantly impact counts. This suggests that either sampling is more thorough or that an increase in detection probability occurs with up to five people, independent of the density of debris at the site (Hardesty et al., 2017b; Burgess et al., 2020). Mechanisms for these two biases have been proposed by Hardesty et al. (2017b). In terms of sampling effort, with more individuals participating, search areas may begin to overlap, creating the possibility for a given location to be searched multiple times thereby increasing the chance that a debris item is spotted (Hardesty et al., 2017b). Similarly, with more individuals participating, the amount of area that a single individual has to search is reduced, limiting the distance from the participant to a debris item and making it easier to spot (Hardesty et al., 2017b). Larger debris items are more easily spotted and removed. For accumulation surveys where debris items are collected, detection probability may shift toward smaller items as participants more actively seek out debris for removal (Hardesty et al., 2017b).

The non-linear relationship between beach width and debris counts suggests that debris appears to accumulate linearly on beaches of up to about $60-70 \mathrm{~m}$ width, after which counts increase more rapidly. This is likely driven by wider beaches in conjunction with surveys being conducted at low tide, resulting in more debris present for enumeration, particularly in exposed wrack lines. Bowman et al. (1998) reported that debris on Israeli beaches is distributed and arranged in distinct strips as a result of depositional dynamics. Similarly, Olivelli et al. (2020) documented increasing debris density moving from the waterline to the backshore suggesting that the backshore area acts as a debris sink vs. other sections of the beach. It is for this reason that debris counts along a given length of beach were modeled as opposed to densities, as densities are highly dependent on the width of the particular beach being surveyed regardless of the total amount of debris that may be present. Although we did not distinguish zones of accumulation within a beach, our results offer some support to previous work.

Although we did not specifically test for the effect of duration of interval between surveys, we found that as the number of days between accumulation surveys increased, the amount of debris observed also increased similar to Hardesty et al. (2017b). This is contrary to studies that have specifically examined how various sampling intervals affect estimates of debris accumulation rates (Swanepoel, 1995; Smith and Markic, 2013). Daily vs. weekly accumulation rates (counts) were 100$600 \%$ greater for two beaches surveyed in Cape Town, South Africa (Swanepoel, 1995) and $\sim 360 \%$ greater for a single beach surveyed in Coffs Harbor, Australia (Smith and Markic, 2013). Smith and Markic (2013) reported that a sampling interval of only 3 days underestimated stranded debris by half and after 1 month, by an order of magnitude (Smith and Markic, 2013). Accumulation rates are largely determined by debris turnover rates which in turn are influenced by varying environmental conditions within and among locations (Bowman et al., 1998) making direct comparison difficult. Debris type also plays a role in turnover rates, with lighter debris turning over more rapidly (i.e., polystyrene foam, Swanepoel, 1995). Thus, it is possible that turnover rates of debris observed on GFNMS and OCNMS beaches were much lower than those reported from previous work, possibly due to a combination of environmental setting and perhaps the presence of heavier debris types. 
There was also some evidence for anthropogenic influence in the amount of debris found on shorelines. By their appearance in the selected models, whether for accumulation, standing stock or both types of surveys, beach access type and distance to nearest town appear to play an important role with regard to the amount of debris at a site which is consistent with previous work. However, it should be emphasized that nothing causative can be concluded about these relationships due to the observational nature of the data, and it is recommended these associations are interpreted with caution due to the limited number of unique covariate levels available between survey sites. A number of studies have reported that shoreline debris densities are significantly higher with proximity to urbanized and high population density areas (Garrity and Levings, 1993; Leite et al., 2014; Hardesty et al., 2017a,b; Vincent et al., 2017). Significantly higher debris loads have also been correlated with increasing proximity to roads (Willis et al., 2017). Beaches close to roads are likely more accessible and therefore may experience higher numbers of visitors, increasing the opportunities for debris deposition via littering (Willis et al., 2017; but see Hardesty et al., 2017a; Olivelli et al., 2020). Increasing numbers of beach visitors have been correlated with increasing litter loads (Frost and Cullen, 1997). Other important variables in predicting accumulation survey plastic loads were related to physical forcing and included tidal range, presence of a freshwater outfall, and distance to nearest river. This is in keeping with previous work which suggests that debris loads are influenced by tidal cycles, namely tide height and especially in combination with wind patterns (Eriksson et al., 2013; Turrell, 2018). Greater amounts of debris have been reported on river-dominated beaches and those located near river mouths (Araujo and Costa, 2007; Santos et al., 2009).

Substrate type can play a role in the distribution and detectability of debris on shorelines (McWilliams et al., 2018; Angelini et al., 2019). Most available methods for shoreline debris monitoring are designed for sandy beaches and must be modified for use on rocky shores (McWilliams et al., 2018) resulting in a paucity of data from these environs (Thiel et al., 2013). On rocky shores of Newfoundland, Canada, McWilliams et al. (2018) found that debris items $>10 \mathrm{~cm}$ were more abundant in the gaps between rocks, at depths of up to $20 \mathrm{~cm}$, rather than on the surface of the shore. Nuances in substrate color combined with debris color can impact accuracy of total debris counts, even on sandy shores (Angelini et al., 2019). Clear debris fragments were under-reported on white and gray sand beaches while counts on brown sand beaches were slightly more accurate (Angelini et al., 2019). Substrate type was not explicitly considered in our analysis due to the resolution at which data were collected. The subset of beaches in this study were either $100 \%$ sand or a varying mixture of sand, cobble, and gravel, even during periods of beach scour when high tides and waves remove sandy surface layers. Since debris counts are only available at the transect level (i.e., rather than say within quadrats with a homogenous substrate type), the proportion of the total debris that was counted over each particular substrate type on mixed-substrate transects is unknown. In the future, it may be worth explicitly stratifying transects over consistent substrate types, or indicating seasonal/monthly changes in substrate type at surveyed sites, in order to tease apart this effect.

Characteristics of the monitoring participants themselves may also influence debris estimates. van der Velde et al. (2017) found that the quality of data collected by citizen scientists (students, teachers, and corporate participants) was equivalent to that collected by professional researchers, although younger primary students detected more debris than secondary students. This potential for increased detectability may be associated with height; primary students are shorter, leading to less visual distance to the beach surface when looking for debris (but see Angelini et al., 2019). Additionally, primary students expressed more interest, engagement, and enthusiasm for monitoring than the older students which also could have resulted in increased detectability (van der Velde et al., 2017). Although not examined here, these certainly warrant further investigation as a means of optimizing current shoreline monitoring methodologies which are dependent on human visual cues (Vegter et al., 2014).

In addition to evaluating potential drivers of marine debris standing stock and accumulation on shorelines, citizen science data has been used to document the effectiveness of legislation aimed at reducing marine debris on shorelines including product bans and container deposit laws (Blickley et al., 2016; Schuyler et al., 2018). Here, standing stock data from the Drakes Beach East monitoring site (Point Reyes National Seashore, GFNMS) documented a $37.5 \%$ decrease in oyster farm debris (e.g., mesh bags and plastic spacer tubes) from data collected in 20122014 compared to data collected in 2015-2017. Although the decrease is not a result of enacted legislation specifically aimed at debris reduction, it is a consequence of Federal land management policy. The decline reflects the expiration of a 40 -year National Park Service lease that resulted in the December 2014 closing of Drake's Bay Oyster Company (Marin County, CA), one of the largest oyster culturing farms on the US West Coast.

Findings from these shoreline monitoring efforts have also been used to identify and support targeted marine debris prevention initiatives. Shotgun wads (custom item) are one of the most common identifiable debris items (excluding fragments) in the GFNMS dataset along with bottle caps, straws, and plastic rope. As the only point-source item, shotgun wad debris' connection to the waterfowl hunting community led to the development and implementation of a behavior change campaign to encourage waterfowl hunters in San Francisco Bay to pick up and properly discard shotgun wads. The pilot campaign was launched at two hunting reserves during the 2019-2020 California waterfowl hunting season; findings from this study were incorporated in behavior change messaging through signage posted at both hunting reserves. Similarly, this study revealed that short lengths of plastic yellow rope are a frequent occurrence on OCNMS shorelines. OCNMS used this evidence in outreach to local oyster aquaculture facilities that are thought to be the source of the yellow rope pieces. 


\section{CONCLUSION}

Findings from this study and other monitoring efforts (mentioned above) illustrate that detecting trends in debris loads can be challenging. For instance, this study shows the utility of long-term monitoring datasets, especially when trying to separate out smaller "episodic" debris events vs. long-term trends. When analyzing only the GFNMS accumulation data, we saw a linear decrease in debris concentrations, however, when comparing this with the longer-term sampling window of the standing stock data, we observed initially low debris counts peaking in 2014-2016, and then declining (e.g., nonlinear relationship). Results also indicated that seasonality may affect expected debris loads, with more debris found on beaches in winter and spring (downwelling) months in the OCNMS compared to other seasons. Thus, it is important to understand the local oceanographic processes that might be driving seasonal changes. In addition to seasonality, other environmental and anthropogenic factors may be influential with regards to debris counts, such as beach access type and the distance to the nearest town. If these variables are of interest in future efforts, they should be considered more in-depth when designing the monitoring program to more confidently analyze these potential drivers with regard to debris trends.

Monitoring efforts from these sanctuaries also demonstrate the benefit of conducting long-term monitoring, especially to measure changes in debris loads following management and/or policy decisions and implementation. Though opportunistic in this case, baseline monitoring should be considered prior to future marine debris policy implementation. Lastly, these modeling exercises provided additional evidence that by standardizing the search effort in our protocol, we can improve the effectiveness of our monitoring design and the robustness of our citizen science shoreline monitoring program.

\section{DATA AVAILABILITY STATEMENT}

The datasets presented in this study can be found in an online repository. The name of the repository can be found at the website listed here and access will be granted via registration for a free account: https://mdmap.orr.noaa.gov/register/.

\section{AUTHOR CONTRIBUTIONS}

AU conceived of and administered the study, wrote the original draft, reviewed, and edited the manuscript. SL provided oversight and curated the shoreline monitoring data, wrote the original draft and reviewed, and edited the manuscript. $\mathrm{CH}$ curated the shoreline monitoring data, wrote the original draft and reviewed, and edited the manuscript. KD conducted statistical analyses, created data visualizations, wrote the original draft and reviewed, and edited the manuscript. $\mathrm{KB}$ acquired the monitoring data for GFNMS and reviewed and edited the manuscript. CB-M acquired the monitoring data for OCNMS and reviewed and edited the manuscript. All authors contributed to the article and approved the submitted version.

\section{FUNDING}

Direct support for open access publication fees was received from the NOAA Marine Debris Program. Indirect support was received from the NOAA Marine Debris Program (AU), the NOAA Southeast Fisheries Science Center (KD), I.M. Systems Group ( $\mathrm{CH}$ and SL), Greater Farallones Association (KB), Greater Farallones Association (KB), and National Marine Sanctuary Foundation (CB-M).

\section{ACKNOWLEDGMENTS}

We appreciate the dedication of all volunteers who generously donated their time to this data collection (B. Bowser, S. Allen, D. Richard, A. Schreiber, H. Reed, S. Darr, C. Kania, B. Siegel, B. Cataldo, Tomales High School, Notre Dame High School, Lodestar Community Charter School, Saint John's Academy, Half Moon Bay High School, L. Antrim, E. Bowlby, M. S. Brancato, J. Bruening, T. Clouse, B. Dalton, D. Easton, N. Fuller, S. Griffith, T. Harris, J. Jewell, R. Johns, L. Johnson, M. Jones, M. Juran, P. Kolenskoff, G. Korb, J. Kristofferson, R. Lewis, D. Lieberman, J. Marks, R. Martinez, B. Maxwell, J. Nelson, J. Oja, J. Pagel, K. Pagel, P. Parker, S. Parker, K. Petersen, D. Rapier, I. Rapier, J. Roberts, J. Roberts, T. Roche, P. Schoen, J. Schroeder, J. Schroeder, E. Shapiro, C. Stokes, M. Tetreau, C. Thomas, C. Turner, K. Turrey, N. Uziemblo, C. Volk, H. Warren, and R. Warren). We thank N. Wilkins for database development and L. Tapawan for data QA/QC. We appreciate the work of previous OCNMS survey leads H. Pedersen and K. Langjahr, and the help of Greater Farallones Association intern L. Hayashigatani. Comments provided by S. Lundgren, A. Mason, N. Wallace, and two journal reviewers strengthened the manuscript. The scientific results and conclusions, as well as any views or opinions expressed herein, are those of the authors and do not necessarily reflect the views of NOAA or the Department of Commerce.

\section{SUPPLEMENTARY MATERIAL}

The Supplementary Material for this article can be found online at: https://www.frontiersin.org/articles/10.3389/fenvs. 2020.604927/full\#supplementary-material

\section{REFERENCES}

Ambrose, K. K., Box, C., Boxall, J., Brooks, A., Eriksen, M., Fabres, J., et al. (2019). Spatial trends and drivers of marine debris accumulation on shorelines in South

Eleuthera, the bahamas using citizen science. Mar. Poll. Bull. 142, 145-154. doi: 10.1016/j.marpolbul.2019.03.036

Angelini, Z., Kinner, N., Thibault, J., and Fuld, K. (2019). Marine debris visual identification assessment. Mar. 
Poll. Bull. 142, 69-75. doi: 10.1016/j.marpolbul.2019. 02.044

Araujo, M. C., and Costa, M. (2007). An analysis of the riverine contribution to the solid wastes contamination of an isolated beach at the Brazilean Northeast. Manag. Environ. Qual. 18, 6-12. doi: 10.1108/14777830710717677

Araujo, M. C. B., Silva-Cavalcanti, J. S., and Costa, M. F. (2018). Anthropogenic litter on beaches with different levels of development and use: a snapshot of a coast in pernambuco (Brazil). Front. Mar. Sci. 5:233. doi: 10.3389/fmars.2018.00233

Bimrose, K., Lindquist, K., and Roletto, J. (2018). Marine Debris - Monitoring and Assessment Program at Greater Farallones National Marine Sanctuary. Marine Sanctuaries Conservation Series ONMS-18-XX. U.S. Department of Commerce, National Oceanic and Atmospheric Administration. Silver Spring, MD: Office of National Marine Sanctuaries. Available online at: https:// clearinghouse.marinedebris.noaa.gov/documents/60819/185732/upload_ 00004737.pdf (accessed October 16, 2020).

Blickley, L. C., Currie, J. J., and Kaufman, G. D. (2016). Trends and drivers of debris accumulation on maui shorelines: implications for local mitigation strategies. Mar. Pol. Bull. 105, 292-298. doi: 10.1016/j.marpolbul.2016.02.007

Bowman, D., Manor-Samsonov, N., and Golik, A. (1998). Dynamics of litter pollution on israeli mediterranean beaches: a budgetary, litter flux. J. Coast. Res. $14,418-432$

Bucci, K., Tulio, M., and Rochman, C. M. (2020). What is known about the effects of plastic pollution: a meta-analysis and systematic review. Ecol. App. 30:e02044. doi: 10.1002/eap.2044

Burgess, H. K., Jones, T. T., Lindsey, J. K., and Parrish, J. K. (2020). Examining Influences on Observed Counts of Shoreline Surveys of Marine Debris. Final Report to the NOAA Marine Debris Program under NOAA Cooperative Agreement NA15OAR4320063. Available online at: https://clearinghouse. marinedebris.noaa.gov/project? mode $=$ View\&projectId $=838$ (accessed October $16,2020)$.

Campbell, M. L., Peters, L., McMains, C., de Campos, M. C. R., Sargisson, R. J., Blackwell, B., et al. (2019). Are our beaches safe? Quantifying the human health impact of anthropogenic beach litter on people in New Zealand. Sci. Total Environ. 651, 2400-2409. doi: 10.1016/j.scitotenv.2018. 10.137

Cheshire, A. C., Adler, E., Barbière, J., Cohen, Y., Evans, S., Jarayabhand, S., et al. (2009). UNEP/IOC Guidelines on Survey and Monitoring of Marine Litter. UNEP Regional Seas Reports and Studies No. 186, Intergovernmental Oceanographic Commission. Available online at: https://wedocs.unep.org/ xmlui/handle/20.500.11822/13604 (accessed October 16, 2020).

Cooper, C. B., Dickinson, J., Phillips, T., and Bonney, R. (2007). Citizen science as a tool for conservation in residential ecosystems. Ecol. Soc. 12:11. doi: 10.5751/ES-02197-120211

da Silva, M. L., Castro, R. O., and Sales, A. S. (2018). Marine debris on beaches of arraial do Cabo, RJ, Brazil: an important coastal tourist destination. Mar. Poll. Bull. 130, 153-158. doi: 10.1016/j.marpolbul.2018. 03.026

Derraik, J. B. G. (2002). The pollution of the marine environment by plastic debris: a review. Mar. Poll. Bull. 44, 842-852. doi: 10.1016/S0025-326X(02)00220-5

English, E., Wagner, C., and Holmes, J. (2019). The Effects of Marine Debris on Beach Recreation and Regional Economies in Four Coastal Communities: A Regional Pilot Study. Final Report to the NOAA Marine Debris Program in Fulfillment of NOAA Contract Number DG133C-12-CQ-0018. Available online at: https://marinedebris.noaa.gov/sites/default/files/publications-files/ 2019.07.Econ_.Impacts.Marine.Debris.complete.wFN_30Aug2019_508.pdf (accessed October 16, 2020).

Eriksson, C., Burton, H., Fitch, S., Schulz, M., and van den Hoff, J. (2013). Daily accumulation rates of marine debris on sub-Antarctic island beaches. Mar. Poll. Bull. 66, 199-208. doi: 10.1016/j.marpolbul.2012.08.026

Escardo-Boomsma, J., O'Hara, K., and Ribic, C. A. (1995). National Marine Debris Monitoring Program: Volume 1, Final Report to the U.S. Washington, DC: Environmental Protection Agency.

Frost, A., and Cullen, M. (1997). Marine debris on northern New South wales beaches (Australia): sources and the role of beach usage. Mar. Poll. Bull. 34, 348-352. doi: 10.1016/S0025-326X(96)00149-X

Gall, S. C., and Thompson, R. C. (2015). The impact of debris on marine life. Mar. Pollut. Bull. 92, 170-179. doi: 10.1016/j.marpolbul.2014.12.041
García-Reyes, M., and Largier, J. L. (2012). Seasonality of coastal upwelling off central and northern California: new insights, including temporal and spatial variability. J. Geophys. Res. 117:C03028. doi: 10.1029/2011JC007629

Garrity, S. D., and Levings, S. C. (1993). Marine debris along the caribbean coast of panama. Mar. Poll. Bull. 26, 317-324. doi: 10.1016/0025-326X(93)90574-4

GFNMS (2014). Gulf of the Farallones National Marine Sanctuary Final Management Plan: Updated in Response to the Sanctuary Expansion. Silver Spring, MD: U.S. Department of Commerce; National Oceanic and Atmospheric Administration; Office of National Marine Sanctuaries. Available online at: https://farallones.noaa.gov/manage/management_plan. html (accessed October 16, 2020).

Graham, W. M., and Largier, J. L. (1997). Upwelling shadows as nearshore retention sites: the example of northern Monterey Bay. Cont. Shelf Res. 17, 509-532. doi: 10.1016/S0278-4343(96)00045-3

Greater Farallones NationalMarine Sanctuary (GFNMS) (2017). About the Greater Farallones National Marine Sanctuary. Availble online at: https://farallones. noaa.gov/about/welcome.html (accessed October 16, 2020).

Haarr, M. L., Pantalos, M., Hartviksen, M. K., and Gressetvold, M. (2020). Citizen science data indicate a reduction in beach litter in the Lofoten archipelago in the Norwegian Sea. Mar. Poll. Bull. 153:111000. doi: 10.1016/j.marpolbul.2020.111000

Hardesty, B. D., Lawson, T. J., van der Velde, T., Lansdell, M., and Wilcox, C. (2017a). Estimating quantities and sources of marine debris at a continental scale. Front. Ecol. Environ. 15, 18-25. doi: 10.1002/fee.1447

Hardesty, B. D., Wilcox, C., Schuyler, Q., Lawson, T. J., and Opie, K. (2017b). Developing a Baseline Estimate Of Amounts, Types, Sources and Distribution of Coastal Litter - An Analysis of US Marine Debris Data (CSIRO: EP167399). Final Report to the NOAA Marine Debris Program in fulfillment of NOAA Award Number NA15NOS4630201. Available online at: https://marinedebris. noaa.gov/sites/default/files/publications-files/An_analysis_of_marine_debris_ in_the_US_FINAL_REP.pdf (accessed October 16, 2020).

Hoellein, T. J., Westhoven, M., Lyandres, O., and Cross, J. (2015). Abundance and environmental drivers of anthropogenic litter on 5 Lake Michigan beaches: a study facilitated by citizen science data collection. J. Great Lakes Res. 41, 78-86. doi: 10.1016/j.jglr.2014.12.015

Hong, S., Lee, J., Kang, D., Choi, H. W., and Ko, S. H. (2014). Quantities, composition, and sources of beach debris in Korea from the results of nationwide monitoring. Mar. Poll. Bull. 84, 27-34. doi: 10.1016/j.marpolbul.2014.05.051

Hong, S., Lee, J., and Lim, S. (2017). Navigational threats by derelict fishing gear to navy ships in the Korean seas. Mar. Pollut. Bull. 119, 100-105. doi: 10.1016/j.marpolbul.2017.04.006

Hothorn, T., Bretz, F., and Westfall, P. (2008). Simultaneous inference in general parametric models. Biometrical J. 50, 346-363. doi: 10.1002/bimj.200810425

Hutto, R. L., and Belote, R. T. (2013) Distinguishing four types of monitoring based on the questions they address. For. Ecol. Manag. 289, 183-189. doi: 10.1016/j.foreco.2012.10.005

Kako, S., Isobe, A., Kataoka, T., Yufu, K., Sugizono, S., Plybon, C., et al. (2018). Sequential webcam monitoring and modeling of marine debris abundance. Mar. Poll. Bull. 132, 33-43. doi: 10.1016/j.marpolbul.2018.04.075

Ko, C. Y., Hsin, Y. C., Yu, T. L., Liu, K. L., Shiah, F. K., and Jeng, M. S. (2018). Monitoring multi-year macro ocean litter dynamics and backward-tracking simulation of litter origins on a remote island in the South China Sea. Environ. Res. Lett. 13:044021. doi: 10.1088/1748-9326/aaaf21

Leeworthy, V., Schwarzmann, D., and Reyes Saade, D. (2015). A Socioeconomic Profile of Recreation Users of the California Northern Central Coast Region, Greater Farallones National Marine Sanctuary and the Northern Portion of Monterey Bay National Marine Sanctuary, 2011. Marine Sanctuaries Conservation Series ONMS-15-11. Silver Spring, MD: U.S. Department of Commerce; National Oceanic and Atmospheric Administration; Office of National Marine Sanctuaries. Available online at: https://montereybay.noaa. gov/research/techreports/trleeworthy2015.html (accessed October 16, 2020).

Leggett, C. G., Scherer, N., Haab, T. C., Bailey, R., Landrum, J. P., and Domanski, A. (2018). Assessing the economic benefits of reductions in marine debris at Southern California beaches: a random utility travel cost model. Mar. Resource Econ. 33, 133-153. doi: 10.1086/697152

Leite, A. S., Santos, L. L., Costa, Y., and Hatje, C. V. (2014). Influence of proximity to an urban center in the pattern of contamination by 
marine debris. Mar. Poll. Bull. 81, 242-247. doi: 10.1016/j.marpolbul.2014. 01.032

Lippiatt, S., Opfer, S., and Arthur, C. (2013). Marine Debris Monitoring and Assessment. U.S. Department of Commerce; NOAA Technical Memorandum NOS-OR\&R-46. Available online at: https://marinedebris.noaa.gov/protocoldocuments/technical-memo-marine-debris-monitoring-and-assessment (accessed October 16, 2020).

Lovett, G. M., Burns, D. A., Driscoll, C. T., Jenkins, J. C., Mitchell, M. J., Rustad, L., et al. (2007). Who needs environmental monitoring? Front. Ecol. Environ. 5, 253-260. doi: 10.1890/1540-9295(2007)5253:WNEM2. $0 . \mathrm{CO} ; 2$

Mæland, C. E., and Staupe-Delgado, R. (2020). Can the global problem of marine litter be considered a crisis? Risk Hazards Crisis Public Policy 11, 87-104. doi: $10.1002 /$ rhc3.12180

McWilliams, M., Liboiron, M., and Wiersma, Y. (2018). Rocky shoreline protocols miss microplastics in marine debris surveys (Fogo Island, Newfoundland and Labrador). Mar. Poll. Bull. 129, 480-486. doi: 10.1016/j.marpolbul.2017. 10.018

Moriarity, M., Pedreschi, D., Stokes, D., Dransfeld, L., and Reid, D. G. (2016). Spatial and temporal analysis of litter in the celtic Sea from groundfish survey data: lessons for monitoring. Mar. Poll. Bull. 103, 195-205. doi: 10.1016/j.marpolbul.2015. 12.019

National Marine Fisheries Service (NMFS) (2018). Fisheries Economics of the United States, 2016. U.S. Department of Commerce, NOAA Technical Memorandum NMFS-F/SPO-187. Available online at: https://www.fisheries. noa.gov/resource/document/fisheries-economics- united-states-report-2016 (accessed October 16, 2020).

National Oceanic and Atmospheric Administration (NOAA) (2016). Report on Marine Debris Impacts on Coastal and Benthic Habitats. Silver Spring, MD: U.S. Department of Commerce; National Oceanic and Atmospheric Administration; Marine Debris Program. Available online at: https:// marinedebris.noaa.gov/sites/default/files/publications-files/Marine_Debris_ Impacts_on_Coastal_\%26_Benthic_Habitats.pdf (accessed October 16, 2020).

Nelms, S. A., Coombes, C., Foster, L. C., Galloway, T. S., Godley, B. J., Lindeque, P. K., et al. (2017). Marine anthropogenic litter on British beaches: a 10-year nationwide assessment using citizen science data. Sci. Total Environ. 579, 1399-1409. doi: 10.1016/j.scitotenv.2016. 11.137

Newman, S., Watkins, E., Farmer, A., Ten Brink, P., and Schweitzer, J. P. (2015). "The economics of marine litter," in Marine Anthropogenic Litter, eds M. Bergmann, L. Gutow, and M. Klages (Cham: Springer International Publishing), 367-394. doi: 10.1007/978-3-319-165103_14

Olivelli, A., Hardesty, B. D., and Wilcox, C. (2020). Coastal margins and backshores represent a major sink for marine debris: insights from a continentalscale analysis. Environ. Res. Lett. 15:074037. doi: 10.1088/1748-9326/a b7836

Olympic Coast National Marine Sanctuary (OCNMS) (2011). Olympic Coast National Marine Sanctuary Final Management Plan and Environmental Assessment. Silver Spring, MD: U.S. Department of Commerce; National Oceanic and Atmospheric Administration. Available online at: https:// nmssanctuaries.blob.core.windows.net/sanctuaries-prod/media/archive/ management/mpr/ocnms_final_plan.pdf (accessed October 16, 2020).

OSPAR Commission (2010). Guideline for Monitoring Marine Litter on the Beaches in the OSPAR Maritime Area, Edition 1.0. London: OSPAR Commission. Available online at: https://www.ospar.org/ospar-data//hbox10--02e_ beachlitter\%20guideline_english\%20only.pdf (accessed October 16, 2020).

Piepho, H. P., and Ogutu, J. O. (2002). A simple mixed model for trend analysis in wildlife populations. J. Agric. Biol. Environ. Stat. 7, 350-360. doi: $10.1198 / 108571102366$

Pirhalla, D., Ransibrahmanakul, V., Clark, R., Desch, A., Wayne, T., and Edwards, M. (2009). An Oceanographic Characterization of the Olympic Coast National Marine Sanctuary and Pacific Northwest: Interpretive Summary of Ocean Climate and Regional Processes Through Satellite Remote Sensing. U.S. Silver Spring, MD: Department of Commerce; NOAA Technical Memorandum NOSNCCOS-90. Available online at: https://repository.library.noaa.gov/view/noaa/ 16896 (accessed October 16, 2020).
Ribic, C. A., Sheavly, S. B., Rugg, D. J., and Erdmann, E. S. (2010). Trends and drivers of marine debris on the Atlantic coast of the United States 1997-2007. Mar. Pollut. Bull. 60, 1231-1242. doi: 10.1016/j.marpolbul.2010. 03.021

Ribic, C. A., Sheavly, S. B., Rugg, D. J., and Erdmann, E. S. (2012). Trends in marine debris along the U.S. Pacific coast and Hawai'i 1998-2007. Mar. Poll. Bull. 64, 994-1004. doi: 10.1016/j.marpolbul.2012. 02.008

Ryan, P. G., Moore, C. J., van Franeker, J. A., and Moloney, C. L. (2009). Monitoring the abundance of plastic debris in the marine environment. Phil. Trans. R. Soc. B 364, 1999-2012. doi: 10.1098/rstb.200 8.0207

Ryan, P. G., Perold, V., Osborne, A., and Moloney, C. L. (2018). Consistent patterns of debris on South African beaches indicate that industrial pellets and other mesoplastic items mostly derive from local sources. Environ. Pollut. 238, 1008-1017. doi: 10.1016/j.envpol.2018. 02.017

Santos, I. R., Friedrich, A. C., and Ivar do Sul, J. A. (2009). Marine debris contamination along undeveloped tropical beaches from northeast Brazil. Environ. Monit. Assess. 148, 455-462. doi: 10.1007/s10661-008-0175-Z

Scheld, A. M., Bilkovic, D. M., and Havens, K. J. (2016). The dilemma of derelict gear. Sci. Rep. 6:19671. doi: 10.1038/srep 19671

Schulz, M., Clemens, T., Forster, H., Harder, T., Fleet, D., Gaus, S., et al. (2015). Statistical analysis of the results of 25 years of beach litter surveys on the south-eastern North Sea coast. Mar. Environ. Res. 109, 21-27. doi: 10.1016/j.marenvres.2015.04.007

Schulz, M., Neumann, D., Fleet, D. M., and Matthies, M. (2013). A multi-criteria evaluation system for marine litter pollution based on statistical analyses of OSPAR beach litter monitoring time series. Mar. Environ. Res. 92, 61-70. doi: 10.1016/j.marenvres.2013.08.013

Schuyler, Q., Hardesty, B. D., Lawson, T. J., Opie, K., and Wilcox, C. (2018). Economic incentives reduce plastic inputs to the ocean. Mar. Pol. 96, 250-255. doi: 10.1016/j.marpol.2018.02.009

Sheavly, S. B. (2007). National Marine Debris Monitoring Program: Final Program Report, Data Analysis and summary. Prepared for U.S. Environmental Protection Agency by Ocean Conservancy. Available online at: http://www. portalasporta.it/dati_plastica/NMDMP_Report_April_2008.pdf (accessed October 16, 2020).

Sheavly, S. B., and Register, K. M. (2007). Marine debris \& plastics: environmental concerns, sources, impacts and solutions. J. Polym. Environ. 15, 301-305. doi: 10.1007/s10924-007-0074-3

Smith, D. A., and Markic, A. (2013). Estimates of marine debris accumulation on beaches are strongly affected by the temporal scale of sampling. PLoS ONE 8:e83693. doi: 10.1371/journal.pone.0083694

Swanepoel, D. (1995). An Analysis of Beach Debris Accumulation in Table Bay (M.Sc. thesis). University of Cape Town, Cape Town, South Africa.

Thiel, M., Hinojosa, I. A., Miranda, L., Pantoja, J. F., Rivadeneira, M. M., and Vasquez, N. (2013). Anthropogenic marine debris in the coastal environment: a multi-year comparison between coastal waters and local shores. Mar. Poll. Bull. 71, 307-316. doi: 10.1016/j.marpolbul.2013.01.005

Toomey, A. H., and Domroese, M. C. (2013). Can citizen science lead to positive conservation attitudes and behaviors? Hum. Ecol. Rev. 20, 50-62. Available online at: www.jstor.org/stable/24707571

Turrell, W. R. (2018). A simple model of wind-blown tidal strandlines: how marine litter is deposited on a mid-latitude, macro-tidal shelf sea beach. Mar. Poll. Bull. 137, 315-330. doi: 10.1016/j.marpolbul.2018.10.024

van der Velde, T., Milton, D. A., Lawson, T. J., Wilcox, C., Lansdell, M., Davis, G., et al. (2017). Comparison of marine debris data collected by researchers and citizen scientists: is citizen science data worth the effort? Biol. Conserv. 208, 127-138. doi: 10.1016/j.biocon.2016.05.025

Vegter, A. C., Barletta, M., Beck, C., Borrero, J., Burton, H., Campbell, M. L., et al. (2014). Global research priorities to mitigate plastic pollution impacts on marine wildlife. Endanger. Species Res. 25, 225-247. doi: 10.3354/esr00623

Vincent, A., Drag, N., Lyandres, O., Neville, S., and Hoellein, T. (2017). Citizen science datasets reveal drivers of spatial and temporal variation for anthropogenic litter on great lakes beaches. Sci. Total Environ. 577, 105-112. doi: $10.1016 /$ j.scitotenv.2016.10.113 
Whitelaw, G., Vaughan, H., Craig, B., and Atkinson, D. (2003). Establishing the canadian community monitoring network. Environ. Monit. Assess. 88, 409-418. doi: 10.1023/A:1025545813057

Willis, K., Hardesty, B. D., Kriwoken, L., and Wilcox, C. (2017). Differentiating littering, urban runoff and marine transport as sources of marine debris in coastal and estuarine environments. Sci. Rep. 7:44479. doi: 10.1038/srep 44479

Wing, S. R, Largier, J. L., and Botsford, L. W. (1998). Coastal retention and longshore displacement of meroplankton near capes in the eastern boundary currents: examples from the California coast. South Afr. J. Mar. Sci. 19, 119-127. doi: $10.2989 / 025776198784126890$

Wood, S. N. (2011). Fast stable restricted maximum likelihood and marginal likelihood estimation of semiparametric generalized linear models. J. R Stat. Soc. B 73, 3-36. doi: 10.1111/j.1467-9868.2010.00749.x
Conflict of Interest: SL and CH were employed by the company I.M. Systems Group, Inc.

The remaining authors declare that the research was conducted in the absence of any commercial or financial relationships that could be construed as a potential conflict of interest.

Copyright $\odot 2020$ Uhrin, Lippiatt, Herring, Dettloff, Bimrose and Butler-Minor. This is an open-access article distributed under the terms of the Creative Commons Attribution License (CC BY). The use, distribution or reproduction in other forums is permitted, provided the original author(s) and the copyright owner(s) are credited and that the original publication in this journal is cited, in accordance with accepted academic practice. No use, distribution or reproduction is permitted which does not comply with these terms. 